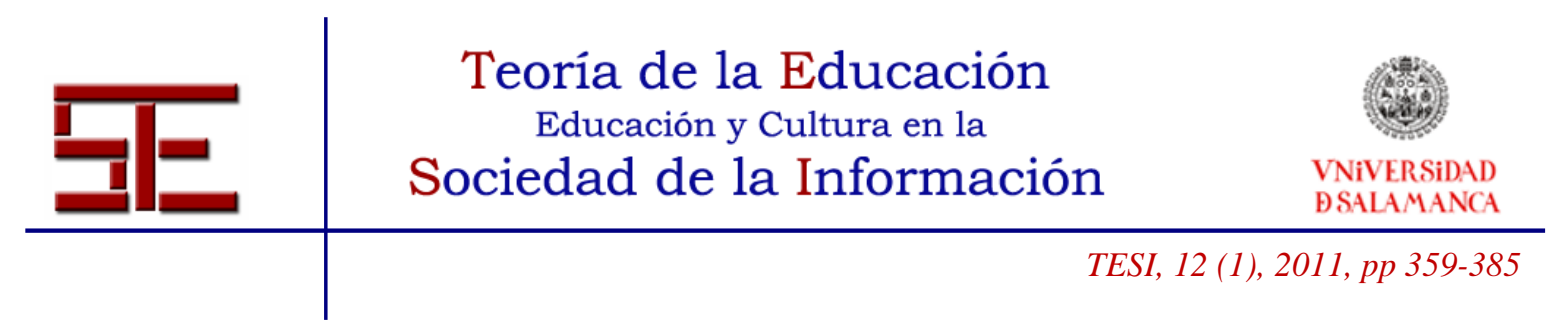

\title{
PRÁCTICAS DE CITACIÓN Y PLAGIO ACADÉMICO EN LA ELABORACIÓN TEXTUAL DEL ALUMNADO UNIVERSITARIO
}

Resumen: Localizar, evaluar, gestionar y comunicar información a la hora de llevar a cabo trabajos académicos se han convertido en competencias básicas que el alumnado universitario debe poseer. En este artículo se presentan los resultados de un estudio descriptivo desarrollado mediante una encuesta con una muestra de 1.025 alumnos pregraduados de la Universidad de las Islas Baleares acerca de la prevalencia en las prácticas de citación y plagio a la hora de elaborar trabajos escritos. De los resultados obtenidos destaca, por un lado, el hecho de que buena parte del alumnado o bien directamente no cita los recursos que emplea en la elaboración de sus trabajos o bien lo hace de manera esporádica o infrecuente. Referente a la comisión de plagio, el porcentaje de alumnado que admite llevar a cabo este tipo de prácticas es ciertamente elevado. Atendiendo a estos datos, así como a los de otros trabajos de similares características, los autores planteamos, en primer lugar, la necesidad de mayores esfuerzos investigadores que permitan conocer de mejor manera las causas de la situación que se describe y seguidamente abogamos por la disposición y realización de acciones formativas que permitan mejorar dicha la situación que se describe.

Palabras clave: alfabetización informacional; plagio académico; educación superior; competencias educativas.

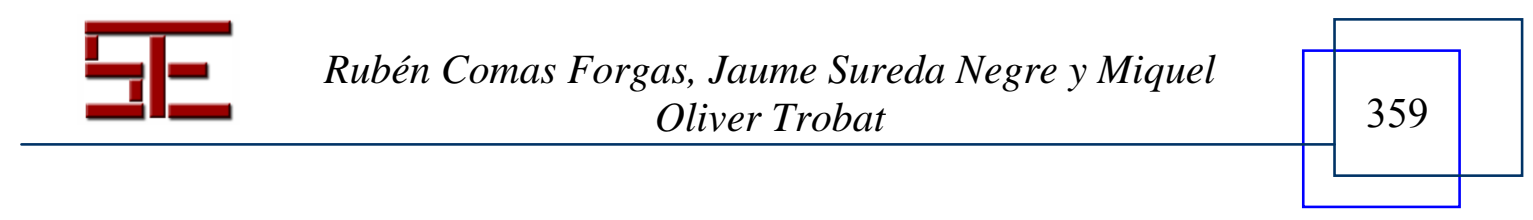




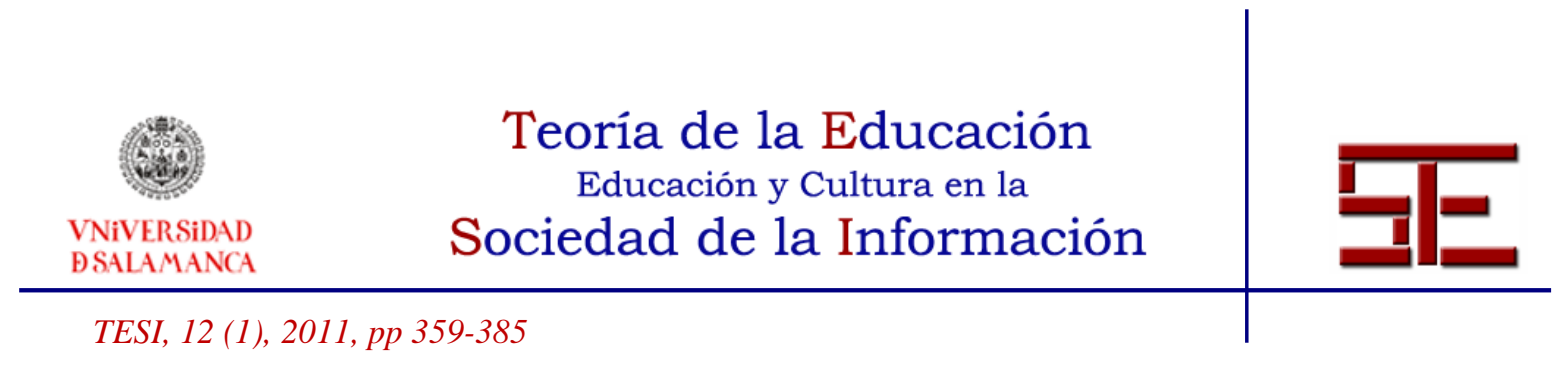

\title{
CITATION PRACTICES AND ACADEMIC PLAGIARISM IN THE TEXTUAL ELABORATION OF UNIVERSITY STUDENTS
}

\begin{abstract}
Locate, evaluate, manage and communicate information in writing academic essays have become basic skills that university students should possess. This article presents the results of a descriptive study developed by survey with a sample of 1.025 under-graduate students at the University of the Balearic Islands on the prevalence in the practice of citation and plagiarism when preparing essays. It should be highlighted from the results obtained, on the one hand, the fact that much of the students or directly do not quote resources used in the preparation of their work or do so sporadically or infrequently. Concerning the commission of plagiarism, the percentage of students who admitted carrying out this type of practice is certainly high. Based on these data, as well as those of other studies with similar characteristics, the authors propose, first, the need for increased research efforts to assess and understand the causes of the situation described and, secondly, advocate for the provision and implementation of training initiatives to improve the situation described.
\end{abstract}

Keywords: information literacy; higher education; academic plagiarism; educational competences.

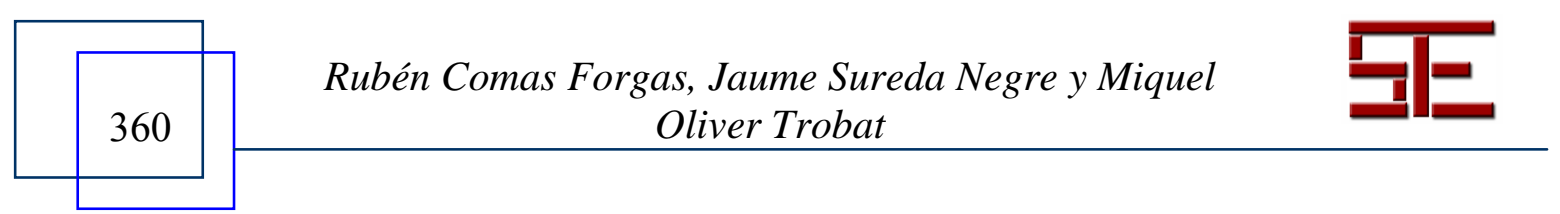




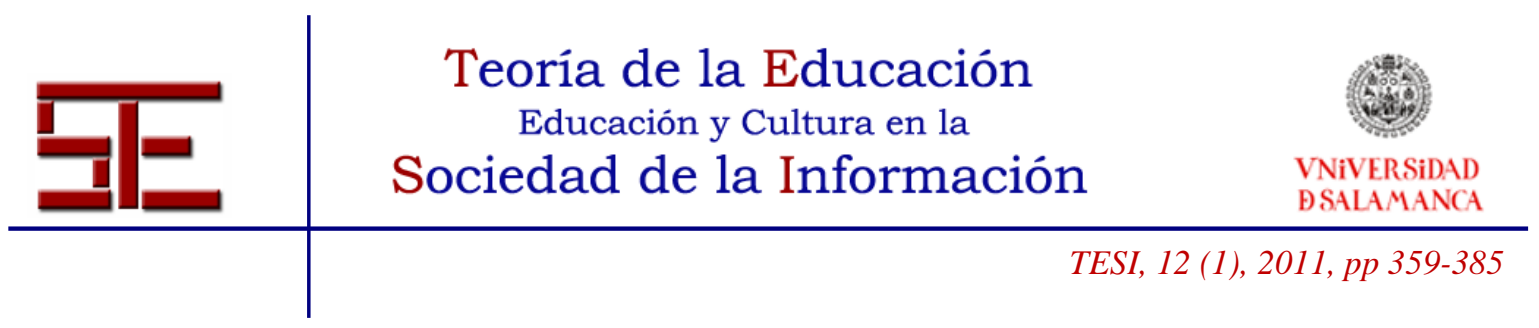

\title{
PRÁCTICAS DE CITACIÓN Y PLAGIO ACADÉMICO EN LA ELABORACIÓN TEXTUAL DEL ALUMNADO UNIVERSITARIO
}

Fecha de recepción: 27/09/2010; fecha de aceptación: 28/01/2011; fecha de publicación: 31/03/2011

\author{
Rubén Comas Forgas \\ rubencomas@uib.es \\ Universidad de las Islas Baleares \\ Jaume Sureda Negre \\ sureda.negre@gmail.com \\ Universidad de las Islas Baleares \\ Miquel Oliver Trobat \\ m.oliver@uib.es \\ Universidad de las Islas Baleares
}

\section{1.- INTRODUCCIÓN}

La cuestión está servida y no se le aventura una ágil ni fácil resolución: cómo encarar en el ámbito de la enseñanza superior la ineluctable consecución de los estándares competenciales de la Alfabetización Informacional (ALFIN, de ahora en adelante) en el escenario de la llamada "Universidad de Google" (Brabazon, 2007), caracterizada, entre otros elementos, por la confusión existente en los sistemas educativos entre facilitar el acceso a la información digital y la formación real de alumnos-ciudadanos capacitados en la localización, gestión, evaluación y comunicación de dicha información en aras de generar conocimiento y aprendizaje $\mathrm{y}$, en segundo término, por la tendencia a la búsqueda de respuestas inmediatas, por parte del alumnado, a la hora de desarrollar actividades de naturaleza académica insertas en su itinerario formativo.

Ciertas transformaciones, para nada singulares, que se han ido dando a lo largo de los últimos veinte años en la institución universitaria española, léase: a) planes de estudio marcados por un aumento del número de asignaturas a cursar por año académico; $b$ ) significadas modificaciones en los procesos de evaluación del alumnado que han supuesto una marcada rebaja del peso de los exámenes de libro cerrado y una intensificación en la importancia de la evaluación basada en el trabajo de curso por parte del alumno ${ }^{4}$ (Moreno-Ariza \& Pérez-Ferra, 2009); y c) la densa masificación de las aulas, combinadas con determinados avances de carácter tecnológico que han generado

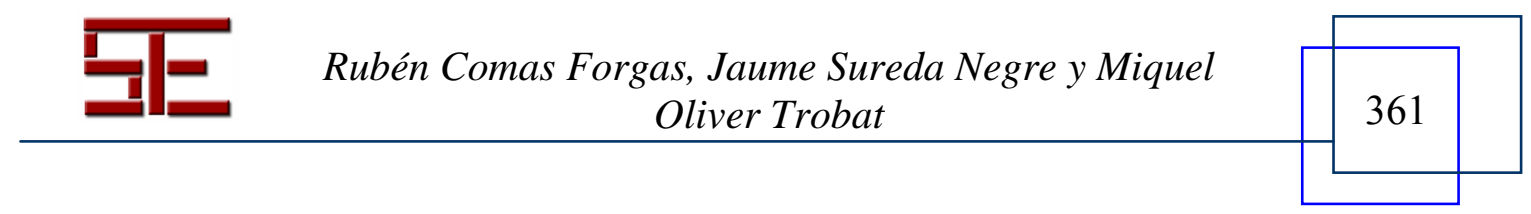




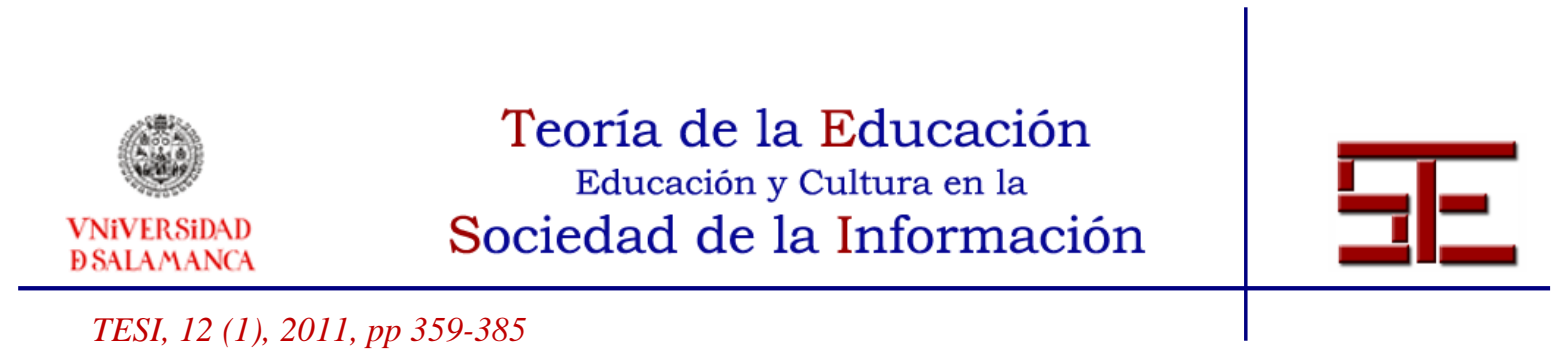

la aparición de una serie de patrones y procedimientos aprehendidos a la hora de localizar, gestionar, tratar y comunicar información con fines educativos que caracterizan a buena parte de la cohorte generacional -los millennials o nativos digitales o la generación google- que transita actualmente por las aulas universitarias (Sureda \& Comas, 2006), nos retornan un mapa de situación en el que el valor del ejercicio de aprender a aprender -a través, entre otras, de las competencias informacionales y desde el angular que sitúa en la autonomía del alumnado el valor medular de la expresióncobra significación máxima y se declama como una necesidad preferente a la que atender desde las instituciones académicas. Es por ello que el desarrollo de las llamadas competencias genéricas (Vickery \& Cooper, 2003) se ha convertido en uno de los ejes vertebradores, a priori y en el papel, sobre el que se asienta el marco pedagógico del Espacio Europeo de Educación Superior (EEES, en adelante).

Existe un prolífico corpus documental en torno a las competencias y capacidades que dan significación y operativizan el concepto de ALFIN. Se trata, sin duda, de un campo de estudio e intervención en plena expansión en el contexto internacional; Rader (2002), cuantifica en algo más de 5.000 las publicaciones aparecidas sobre ALFIN en el ámbito anglosajón entre los años 1973 y 2002. Aun con todo, en el entorno de los países hispanoamericanos, la situación no es tan boyante en términos numéricos, constatándose un importante déficit, sobre todo, de aproximaciones empíricas a la materia (Licea-de-Arenas, 2009).

La ALFIN cobra forma en torno a un conjunto de estándares o competencias que han sido profusamente tratados en la literatura especializada. Imperan una serie de principios básicos, a modo de acuerdo de mínimos, que rigen y aportan contenido a lo que se entiende por ALFIN en entornos académicos; éstos se pueden resumir en: la habilidad de percibir la existencia de una necesidad de información y la capacidad de localizar, evaluar y emplear la información necesaria para cubrir dicha necesidad de manera efectiva y apropiada (CAUL, 2001). Siendo así, dichas competencias van más allá de lo que podría describirse como una alfabetización bibliotecaria y abrazan, entre otros, elementos tales como: la alfabetización digital, la alfabetización computacional, la alfabetización mediática, la ética informacional, el pensamiento crítico y la habilidad comunicativa (Bawden; 2000; Parang, Raine \& Stevenson, 2001).

Las aproximaciones empíricas en forma de estudios y trabajos de investigación desarrollados hasta la fecha suelen tener una notable inclinación hacia el análisis de uno de los campos competenciales anteriormente enumerados: la capacidad para localizar

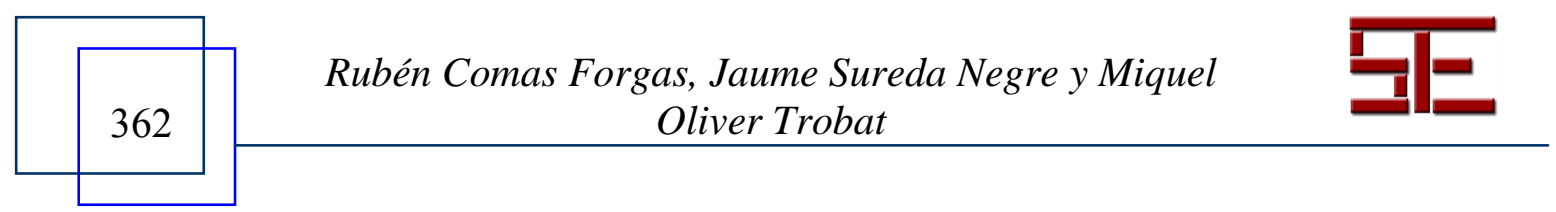




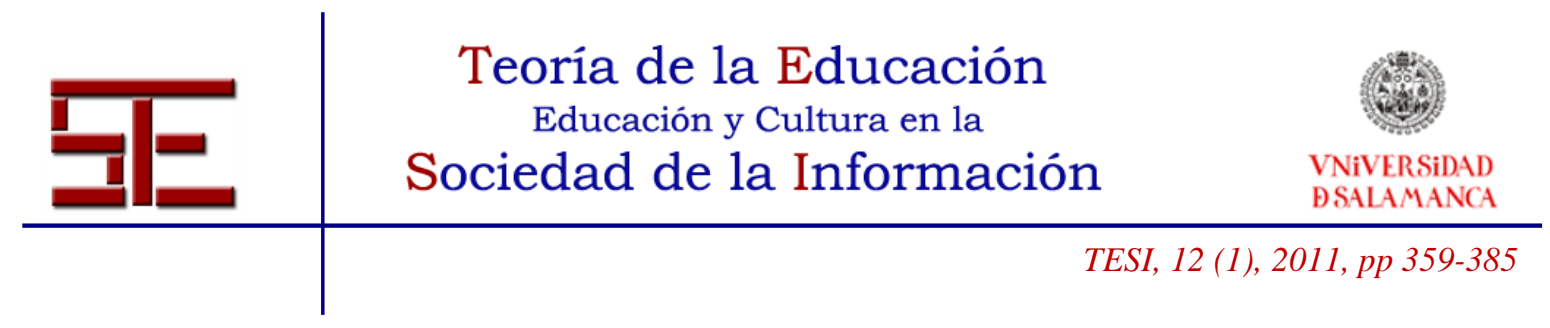

información o, lo que es lo mismo, las estrategias de documentación del alumnado universitario (Aditaka \& Anwar, 2006; Head, 2007; Kuruppu, 2008; Martin, 2009; Zhang, Anghelescu \& Yuan, 2005; Vondraceck, 2007). Estos trabajos intentan responder, entre otras, a cuestiones tales como: ¿qué fuentes documentales consulta el alumnado, generalmente, para elaborar trabajos académicos y/o actividades de índole académica? y ¿qué estrategias de búsqueda siguen los universitarios a la hora de localizar información? (Cmor \& Lippold, 2001; Asemi, 2005; Comas, Sureda \& Mut, 2010); ¿qué uso hace el alumnado de los recursos digitales para documentarse con fines académicos? (Marzal \& Calzada, 2003; Griffiths \& Brophy, 2002; Sureda \& Comas, 2006; McMartin et al., 2008; Nwagwu et al., 2009); y ¿de qué manera y con qué frecuencia emplea el alumnado universitario los fondos documentales de las universidades? (Agosto, Paone \& Ipock, 2007; Arias \& Simón, 2008; Baer \& Li, 2009). Por el contrario, existen exiguos aportes empíricos que se concentren en el estudio de la manera como el alumnado universitario emplea la información localizada de manera ética, legal y socialmente relevante (ACRL/ALA, 2000) cuando elabora trabajos y/o actividades de naturaleza académica. Aunque conviene precisar que, si bien no se trata de estudios puramente alineados en el campo de las competencias informacionales, si existe cuantiosa bibliografía a este respecto desde una perspectiva de análisis enmarcada bajo el paraguas terminológico de la Integridad Académica (IA, en adelante). A pesar de no tratarse de áreas idénticas, no puede negarse que, cuanto menos, comparten numerables elementos que les convierten en una suerte de ámbitos afines. Se distinguen, siguiendo a Comas (2009), tres entornos esenciales asociados al estudio de la IA entre el alumnado: IA ligada al desarrollo de pruebas escritas (exámenes); IA ligada al desarrollo de trabajos y/o actividades académicas evaluables y pertenecientes al itinerario curricular de los estudios; y, por último, IA ligada a actividades propias de la vida académica (uso de los recursos, relación con los compañeros, relación con los docentes, etc.). De tal manera, el punto de conexión entre la ALFIN y la IA estaría circunscrito al segundo de los campos referenciados. Dentro de este contexto se consideran prácticas que atentan contra los principios de la IA las siguientes acciones (ver Tabla I):

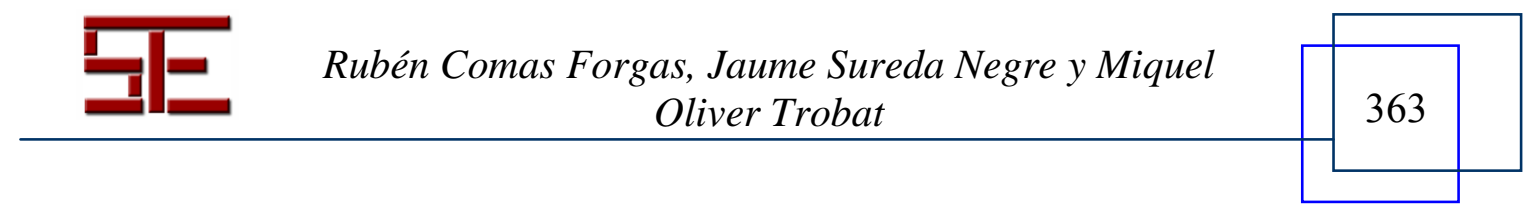




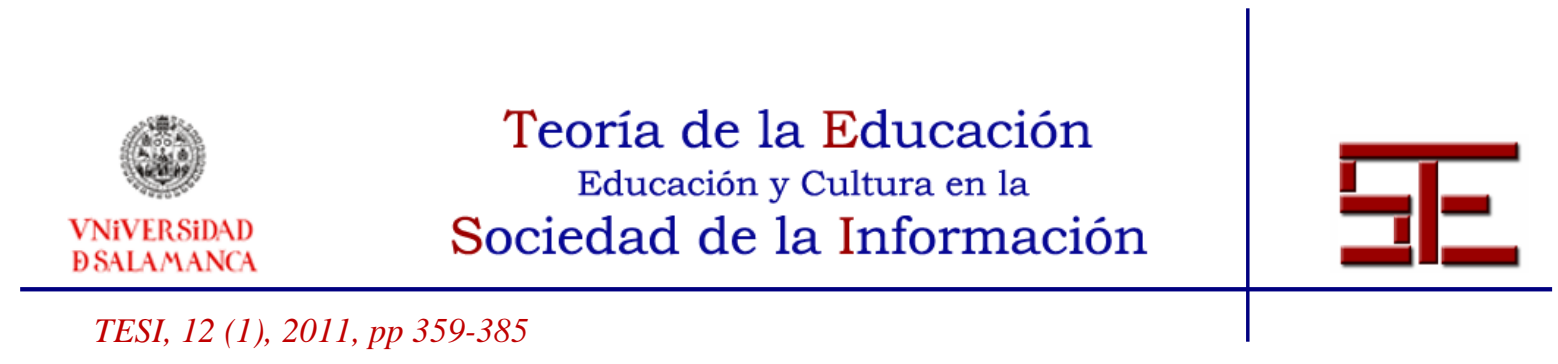

\begin{tabular}{|c|c|c|}
\hline $\begin{array}{l}\text { Acciones y prácticas } \\
\text { académicamente } \\
\text { incorrectas relativas a la } \\
\text { elaboración y presentación } \\
\text { de trabajos académicos }\end{array}$ & $\begin{array}{l}\square \\
\square\end{array}$ & $\begin{array}{l}\text { Ciber-plagio } \\
\circ \quad \text { Copiar de páginas Web u otros recursos accesibles en la Red fragmentos } \\
\text { de textos y -sin citar- pegarlos directamente en un documento - en el que } \\
\text { hay parte de texto original- y entregarlo como trabajo de una asignatura } \\
\circ \quad \text { Elaborar, integramente, un trabajo a partir de fragmentos copiados } \\
\text { literalmente de páginas Web y/o recursos localizados en Internet } \\
\text { Descargar un trabajo completo desde Internet y entregarlo, sin cambios, } \\
\text { como trabajo de una asignatura } \\
\text { Plagio de fuentes impresas } \\
\text { Copiar y no citar fragmentos de textos y documentos impresos (libros, } \\
\text { periódicos, revistas, etc.) } \\
\text { Copiar partes de trabajos entregados en años anteriores (bien sean propios } \\
\text { o sean de otro estudiante) y entregarlos como partes de un trabajo } \\
\text { académico "nuevo" } \\
\text { Entregar un trabajo completo realizado por otro alumno que ya haya sido } \\
\text { entregado en cursos anteriores (para la misma u otra/s asignatura/s) } \\
\text { Entregar un trabajo completo realizado por uno mismo que ya haya sido } \\
\text { entregado (para la misma u otra asignatura) } \\
\text { Facilitar a otro alumno un trabajo de años anteriores o actual para que lo } \\
\text { entregue como un trabajo propio, original e inédito } \\
\text { Elaborar un trabajo académico para que lo entregue otra persona } \\
\text { Compra-venta de trabajos académicos } \\
\text { Falsear la bibliografía y recursos consultados en la elaboración de un trabajo } \\
\text { académico } \\
\text { Falsear datos y resultados en trabajos académicos } \\
\text { Colaborar en la elaboración de un trabajo sin estar permitido }\end{array}$ \\
\hline
\end{tabular}

Tabla I. Acciones contra la IA relativas a la elaboración de trabajos académicos (Fuente: Comas, 2009).

Existe un limitado corpus doctrinal acerca de la IA del alumnado universitario español. Es ésta una cuestión que, hasta la fecha, ha sido minoritariamente abordada y de la que constan escasas reseñas remarcables. La primera a considerar está representada por el trabajo de Blanch-Mur, Rey-Abella y Font-Soler (2006), ajustado al estudio de diversas formas de deshonestidad académica entre el alumnado de la Escuela Universitaria de Enfermería, Fisioterapia y Nutrición Blanquerna. La segundo deviene de un trabajo respaldado por la empresa francesa de desarrollo de software antiplagio Six Degrés (Agnes, 2008) fundamentado en la administración de una encuesta a 299 universitarios y 53 docentes de las universidades de Barcelona y Zaragoza. El tercer estudio, y el más exhaustivo de los llevados a cabo en España en este campo hasta el momento, se realizó investigando una muestra representativa $(n=727)$ del alumnado pregraduado de todas las titulaciones de la Universidad de las Islas Baleares (Sureda et al., 2008a). Del mismo equipo de investigadores es el estudio sobre la IA del alumnado universitario español adscrito al portal UNIVERSIA (Sureda et al., 2008b), que se basó en la encuestación de

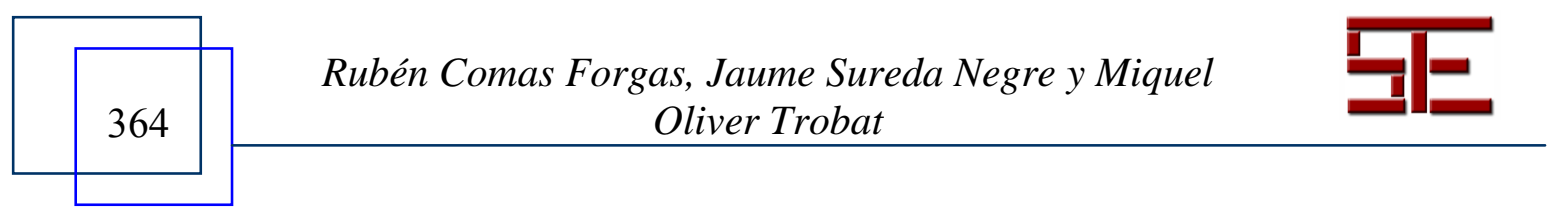




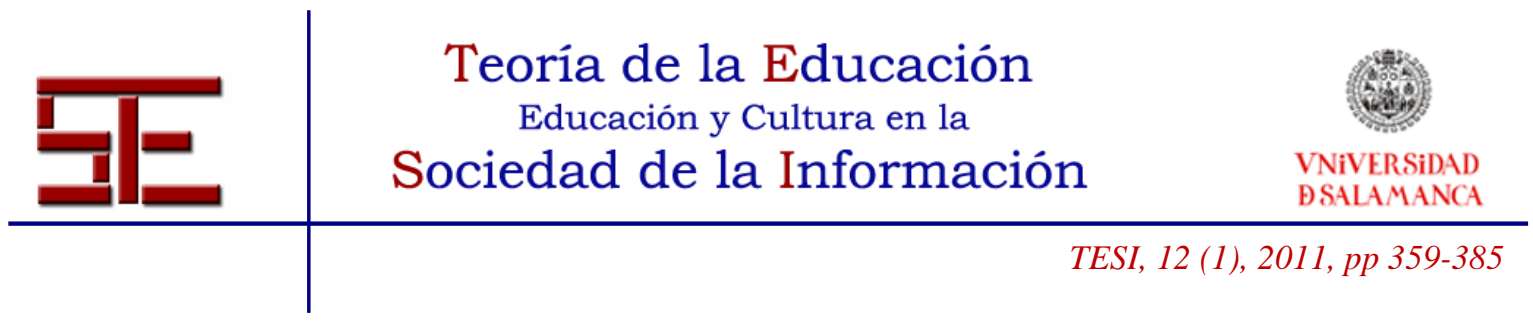

un total de 560 universitarios pre-graduados. Finalmente, destaca la labor de Ballano y Muñoz (2009), quienes analizaron la prevalencia del plagio académico entre el alumnado de la Universidad de Deusto a partir de un estudio basado en el análisis de contenido de trabajos académicos elaborados por alumnado de dicha institución.

Son, asimismo, escasos los trabajos de investigación desarrollados en otros países hispanoamericanos; de entre los que se cuentan conviene resaltar las contribuciones de: Mejías y Ordóñez (2004) que estudiaron la cuestión de la IA entre el alumnado de la universidad colombiana de Los Andes; en Brasil destaca el estudio relativo a la percepción del plagio académico por parte de alumnado de Ingeniería de la Universidad de Río de Janeiro (Garcia-Barbastefano \& Gomes-de-Souza, 2007); por último, en Perú (Saldaña et al, 2010), se efectuó un acreditado trabajo en el que se examinó la prevalencia de la comisión de plagio académico entre las Tesis de Medicina presentadas en una universidad pública de dicho país.

Nuestra propuesta, concretada en el presente artículo, está en la línea de los trabajos acabados de mencionar. Pretende ser una aproximación singular a aspectos que estarían situados dentro del marco competencial de la ALFIN y que al mismo tiempo tienen cabida en el área de estudio descrita como la propia de la IA. Los objetivos que se persiguen son de naturaleza descriptiva y pasan por: a) analizar y especificar la prevalencia de las prácticas de plagio y auto-plagio entre el alumnado universitario a la hora de elaborar trabajos académicos; y b) analizar y exponer la prevalencia en las prácticas de citación entre el alumnado universitario a la hora de elaborar trabajos académicos.

\section{2.- MÉTODO}

\subsection{Muestra y población}

La investigación ha contado con la participación de un total de 1.025 alumnos pregraduados de la Universidad de las Islas Baleares (UIB) seleccionados mediante muestreo aleatorio a partir de la población compuesta por el total de los 11.380 alumnos matriculados en Grados, Diplomaturas, Licenciaturas e Ingenierías en la UIB durante el curso 2009-2010. El tamaño de la muestra con el que se ha trabajado supone un error muestral de $\pm 2,9 \%$, estimado para un nivel de confianza del $95 \%$ y bajo la condición más desfavorable de $\mathrm{p}=\mathrm{q}=0.05$. La recogida de datos se realizó en el Campus de la UIB durante el mes de noviembre de 2009 mediante la aplicación individual y anónima, en diversas aulas del centro, de un cuestionario por parte de cuatro personas previamente

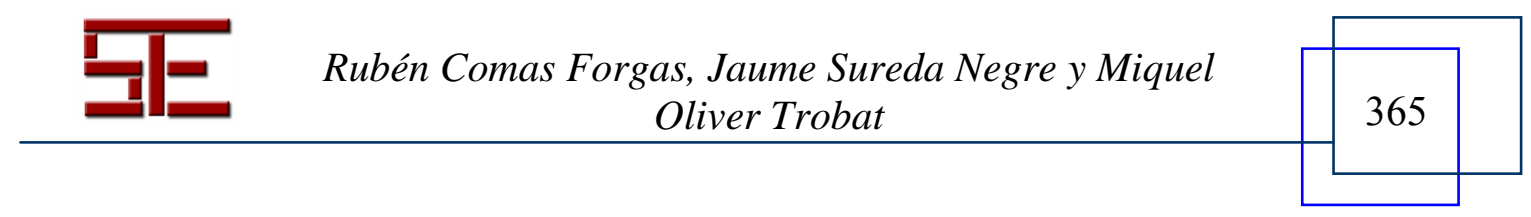




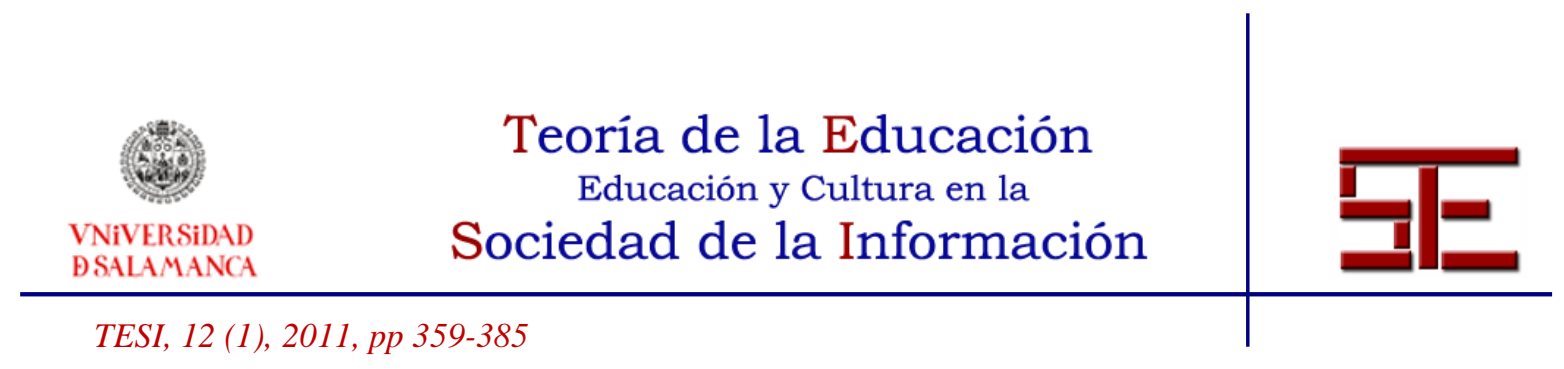

instruidas para desarrollar la tarea. En la Tabla II se exponen las características más destacadas de la muestra con la que se trabajó.

\subsection{Fuente de datos y variables de estudio}

Los datos para la elaboración del presente artículo provienen de la "Encuesta sobre las competencias en Alfabetización Informacional del alumnado de la Universidad de las Islas Baleares", cuya principal finalidad consistía en analizar diversos aspectos sobre las competencias informacionales del alumnado pre-graduado de la UIB; para ello se establecieron cinco ámbitos de análisis que se ajustan a las cinco competencias básicas acordadas internacionalmente en el campo de la ALFIN, siendo: a) Identificación de las necesidades de información; b) Estrategias de búsqueda de información; c) Evaluación y tratamiento de la información; d) Utilización y elaboración de la información, y e) Aspectos éticos y sociales del uso de la información (ACRL/ALA, 2000). El instrumento de recogida de datos constaba de un total de 41 preguntas entre las que había de tipo: abiertas, cerradas dicotómicas, cerradas politómicas, de posición y escalas de respuesta.

Las variables escogidas para conformar el trabajo que aquí se presenta quedan encuadradas en los campos competenciales: "Utilización y elaboración de la información” " “Aspectos éticos y sociales del uso de la información"; y concretamente se operativizan en:

- Comisión de plagio y auto-plagio académico por parte del alumnado universitario a la hora de elaborar y presentar trabajos (puntos 3.1. y subsiguientes).

- Cumplimiento de las normas de citación a la hora de elaborar trabajos académicos por parte del alumnado universitario (puntos 3.2. y subsiguientes).

Con el objetivo de medir la asociación e interacciones entre las variables estudiadas con diversas características de la muestra, se relacionaron los resultados de las dichas variables con diversas categorías y rasgos descriptivos del alumnado participante: género, área de conocimiento de los estudios que cursan y curso matriculado (ver Tabla II).

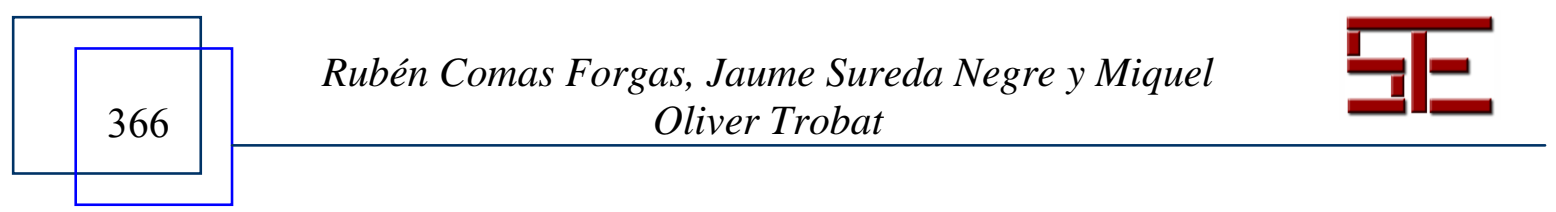




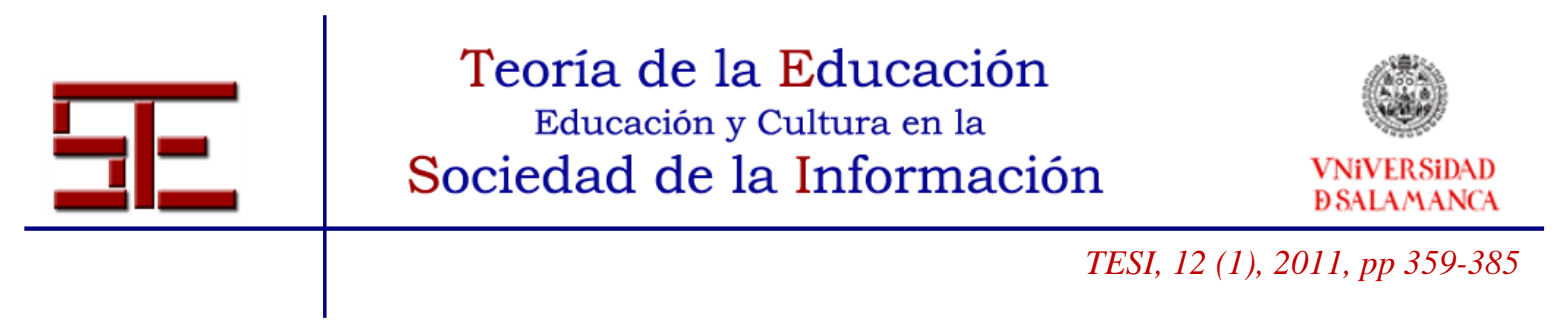

\begin{tabular}{|l|l|l|}
\hline Variable & N & Porcentaje \\
\hline Género: & & \\
Mujer & 670 & $65,5 \%$ \\
Hombre & 353 & $34,5 \%$ \\
\hline Área de conocimiento: & & \\
CC. Experimentales & 165 & $16,1 \%$ \\
CC. Sociales y Jurídicas & 680 & $66,3 \%$ \\
CC. Salud & 134 & $13,1 \%$ \\
Humanidades & 46 & $4,5 \%$ \\
\hline Curso matriculado: & & \\
Primero & 295 & $28,8 \%$ \\
Segundo & 201 & $19,7 \%$ \\
Tercero & 257 & $25,1 \%$ \\
Cuarto & 218 & $21,3 \%$ \\
Quinto & 52 & $5,1 \%$ \\
\hline
\end{tabular}

Tabla II. Características y distribución de la muestra del estudio (tamaño de la muestra $=1.025$ alumnos).

\subsection{Análisis de datos}

Respecto a cada una de las variables de categoría se ha efectuado el cálculo de la frecuencia y el porcentaje, mientras que en las variables de escala se ha establecido el cálculo de la frecuencia, la media y la desviación estándar. Seguidamente, a efecto de poder establecer la posible asociación entre las variables en base a las que se operativizan las competencias estudiadas y las características del alumnado o variables categóricas (Tabla II), se han diseñado tablas de contingencia para cada una de las variables y se ha efectuado la prueba de chi-cuadrado calculándose el coeficiente de correlación de Pearson para, de esta forma, conocer el nivel de significación de las asociaciones originadas. Para todos los análisis descritos se he empleado el paquete estadístico "Statistical Package for the Social Sciences" (SPSS versión 15.0).

\section{3.- RESULTADOS}

3.1. Comisión de plagio y auto-plagio académico por parte del alumnado universitario a la hora de elaborar y presentar trabajos académicos

Tal y como queda recogido en la Tabla III, prácticamente siete de cada diez alumnos encuestados (69.2\%) admiten haber copiado fragmentos de textos o textos completos y haberlos presentado como propios en la entrega de un trabajo académico al menos en una ocasión durante sus estudios en la universidad. El porcentaje que manifiesta haber

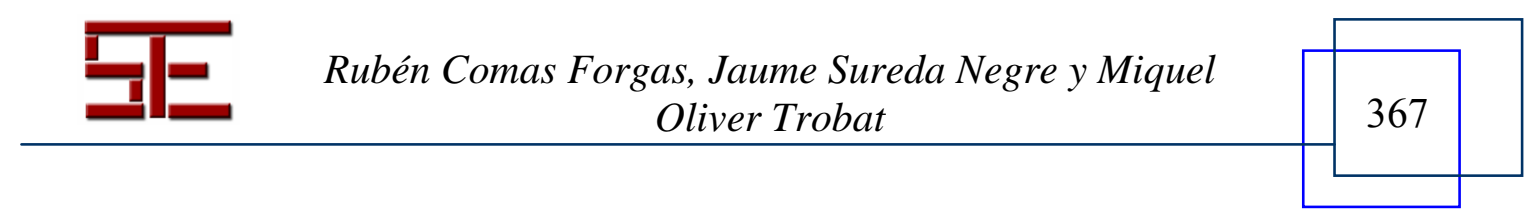




\begin{tabular}{cc}
$\begin{array}{c}\text { Teoría de la Educación } \\
\text { Educación y Cultura en la } \\
\text { VNiVERSIDAD } \\
\text { BSALAMANCA }\end{array}$ & Sociedad de la Información \\
\hline TESI, $12(1), 2011, p p$ & $359-385$
\end{tabular}

llevado a cabo esta práctica en seis o más de seis ocasiones alcanza casi el 25\% (el $10.4 \%$ confirma haber actuado de esta forma entre 6 y 10 ocasiones y el $13.9 \%$ afirma haberlo hecho en más de 10 ocasiones).

\begin{tabular}{|l|l|l|}
\hline $\begin{array}{l}\text { iHas copiado alguna vez, durante tus estudios en la universidad, un fragmento de un } \\
\text { texto o un texto completo y sin referenciar la fuente lo has presentado como tuyo en un } \\
\text { trabajo académico que hayas entregado? }\end{array}$ & $\mathbf{N}$ & Porcentaje \\
\hline No, nunca lo he hecho & 313 & $30.5 \%$ \\
\hline Sí, lo he hecho entre 1 y 5 veces & 460 & $44.9 \%$ \\
\hline Sí, lo he hecho entre 6 y 10 veces & 107 & $10.4 \%$ \\
\hline Sí, lo he hecho en más de 10 ocasiones & 142 & $13.9 \%$ \\
\hline No sabe / No contesta & 3 & $0.3 \%$ \\
\hline Total & $\mathbf{1 . 0 2 5}$ & $\mathbf{1 0 0 \%}$ \\
\hline
\end{tabular}

Tabla III. Frecuencia de comisión de plagio en la elaboración de trabajos académicos

Cerca del $70 \%$ de la muestra $(67.5 \%)$ admite haber llevado a cabo, al menos una vez, la práctica de "reciclar", parcial o totalmente, trabajos ya entregados para componer trabajos nuevos (lo que en la literatura sobre el tema de conoce como auto-plagio). Casi seis de cada diez universitarios preguntados afirman haber actuado de esta manera entre 1 y 5 veces a lo largo de sus estudios en la universidad.

\begin{tabular}{|l|l|l|}
\hline $\begin{array}{l}\text { ¿Has entregado en alguna ocasión, durante tus estudios en la universidad, un trabajo } \\
\text { académico propio (o partes de éste) que ya había sido entregado por ti anteriormente? }\end{array}$ & $\mathbf{N}$ & Porcentaje \\
\hline No, nunca lo he hecho & 327 & $31.9 \%$ \\
\hline Sí, lo he hecho entre 1 y 5 veces & 611 & $59.6 \%$ \\
\hline Sí, lo he hecho entre 6 y 10 veces & 61 & $6 \%$ \\
\hline Sí, lo he hecho en más de 10 ocasiones & 19 & $1.9 \%$ \\
\hline No sabe / No contesta & 7 & $0.6 \%$ \\
\hline Total & $\mathbf{1 . 0 2 5}$ & $\mathbf{1 0 0 \%}$ \\
\hline
\end{tabular}

Tabla IV. Frecuencia de comisión de auto-plagio en la elaboración de trabajos académicos

De las categorías de la muestra examinadas (recuérdese: género, curso y área de conocimiento), destaca la existencia de diferencias internas estadísticamente significativas en las tres cuando se asocian con la frecuencia en la comisión de plagio y la categoría género cuando ésta se vincula con la frecuencia de comisión de auto-plagio (ver Tabla V).

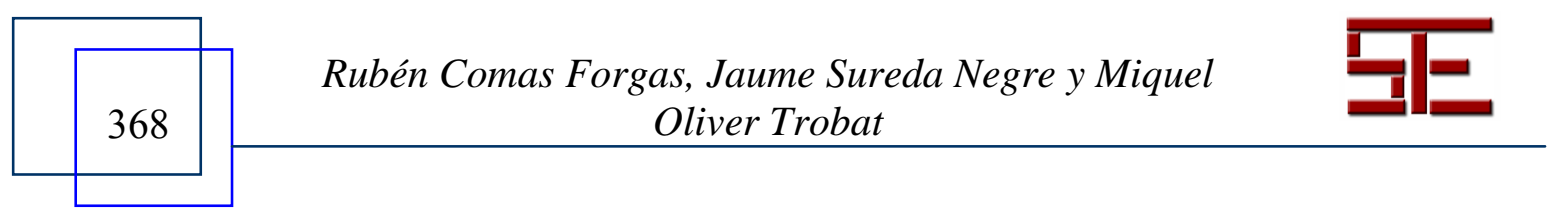




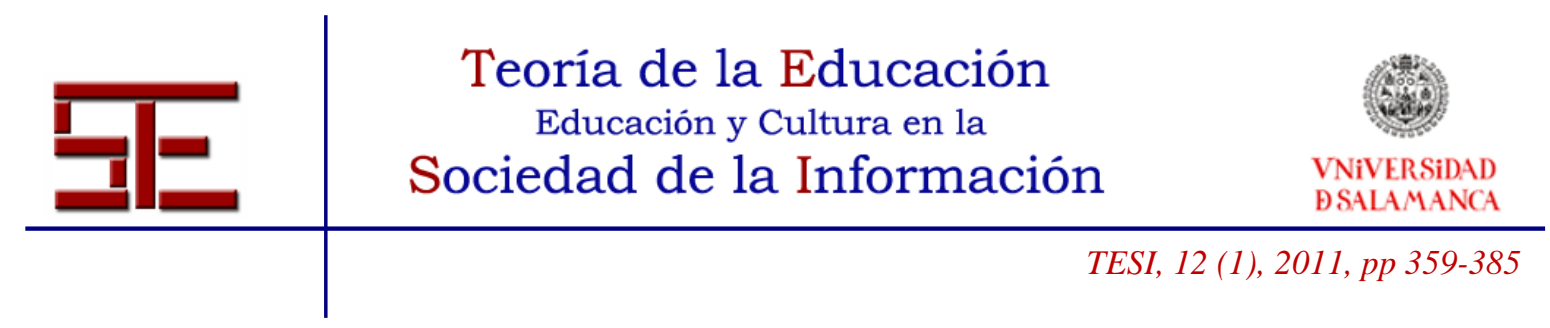

\begin{tabular}{|l|l|l|l|l|l|l|l|l|}
\hline & \multicolumn{6}{|l|}{$\begin{array}{l}\text { Copiar un texto (completo o fragmentos) y sin } \\
\text { referenciar la fuente entregarlo como propio }\end{array}$} & \multicolumn{2}{l|}{$\begin{array}{l}\text { Entregar un trabajo propio que ya } \\
\text { había sido entregado }\end{array}$} \\
\hline $\begin{array}{l}\text { Características de } \\
\text { la muestra }\end{array}$ & $\chi^{2}$ & $\boldsymbol{p}$ & $\mathbf{g . l .}$ & $\mathbf{n}$ & $\chi^{2}$ & $\boldsymbol{p}$ & g.l. & $\mathbf{n}$ \\
\hline Género & $55,285^{*}$ & 0,000 & 3 & 1.020 & $14,273^{*}$ & 0,003 & 3 & 1.016 \\
\hline Curso matriculado & $53,630^{*}$ & 0,000 & 12 & 1.022 & 23,797 & 0,022 & 12 & 1.018 \\
\hline $\begin{array}{l}\text { Área } \\
\text { conocimiento }\end{array}$ & $53,428^{*}$ & 0,000 & 9 & 1.022 & 11,123 & 0,267 & 9 & 1.018 \\
\hline
\end{tabular}

Tabla V: Valor de la prueba de chi-cuadrado de Pearson para la asociación entre la comisión de plagio y auto-plagio en trabajos académicos y las características del alumnado.

$\chi^{2}$ Chi-cuadrado de Pearson // p Significación // g.l. Grados de libertad // * Significativa al nivel 0,01 (bilateral) // n

$\mathrm{N}^{\mathrm{o}}$ alumnos de la muestra

Como puede comprobarse en la Gráfica 1, las universitarias presentan tasas bastante más elevadas en los niveles intermedios de frecuencia en la comisión de plagio en la universidad (entre una y diez ocasiones); mientras que los alumnos muestran frecuencias más pronunciadas en las posiciones más extremas (no han copiado nunca un texto completo o partes de éste y sin referenciar la fuente lo han entregado como propio o lo han hecho más de diez veces).

\section{Gráfica 1:}

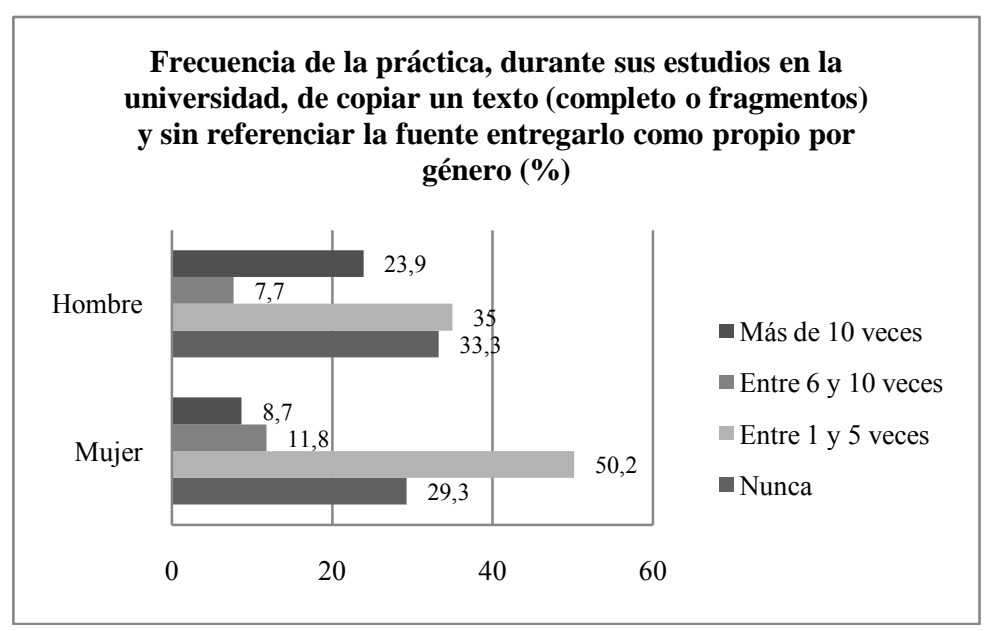

Rubén Comas Forgas, Jaume Sureda Negre y Miquel Oliver Trobat 


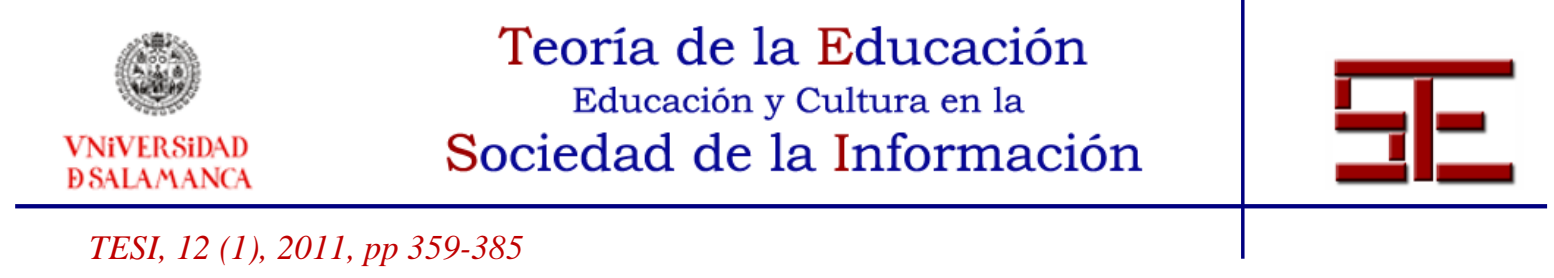

A la vista de los resultados obtenidos en esta cuestión -comisión de plagio en la elaboración de trabajos-, relacionados con el curso que estudian los participantes en el estudio (ver Gráfica 2), se desprende que el alumnado de cursos superiores o de segundo ciclo (cuarto y, sobre todo, quinto) presentan niveles más bajos que el resto de alumnado en cuanto a la frecuencia declarada de la práctica consistente en elaborar trabajos a partir de copiar textos enteros o fragmentos de textos.

\section{Gráfica 2:}

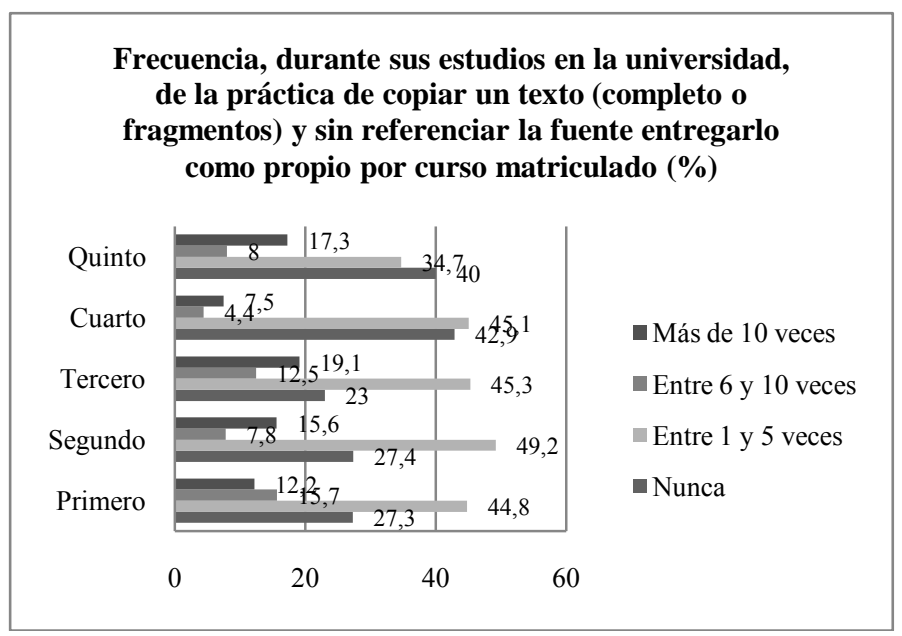

El alumnado perteneciente a carreras del área de las Humanidades es el que manifiesta valores más bajos, con una relevante diferencia respecto al resto, en la prevalencia de la práctica de plagiar trabajos en el transcurso de sus estudios en la universidad (ver Gráfica 3). Los alumnos de Ciencias Sociales se posicionan, de manera general, en niveles moderados; al igual que sucede con el alumnado de Ciencias de la Salud. Los estudiantes matriculados en carreras del área de las Ciencias Experimentales manifiestan índices de prevalencia elevada más consistentes que el resto.

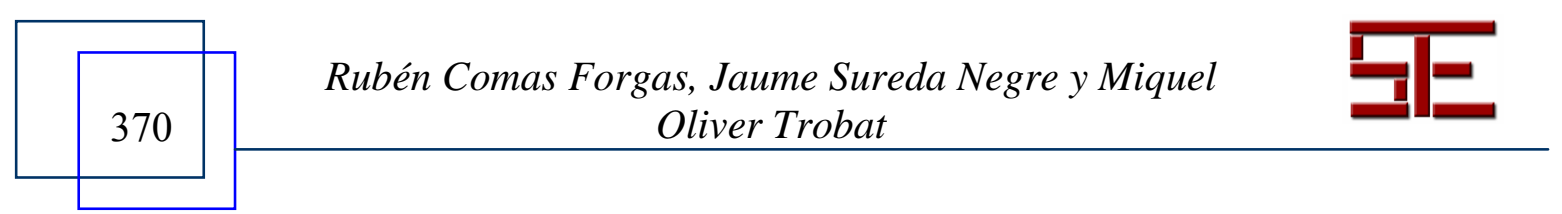




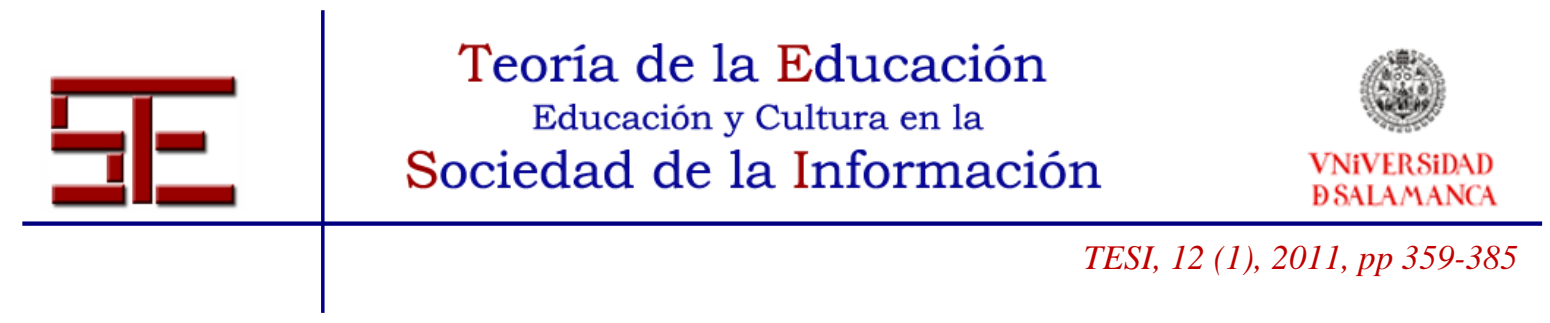

\section{Gráfica 3:}

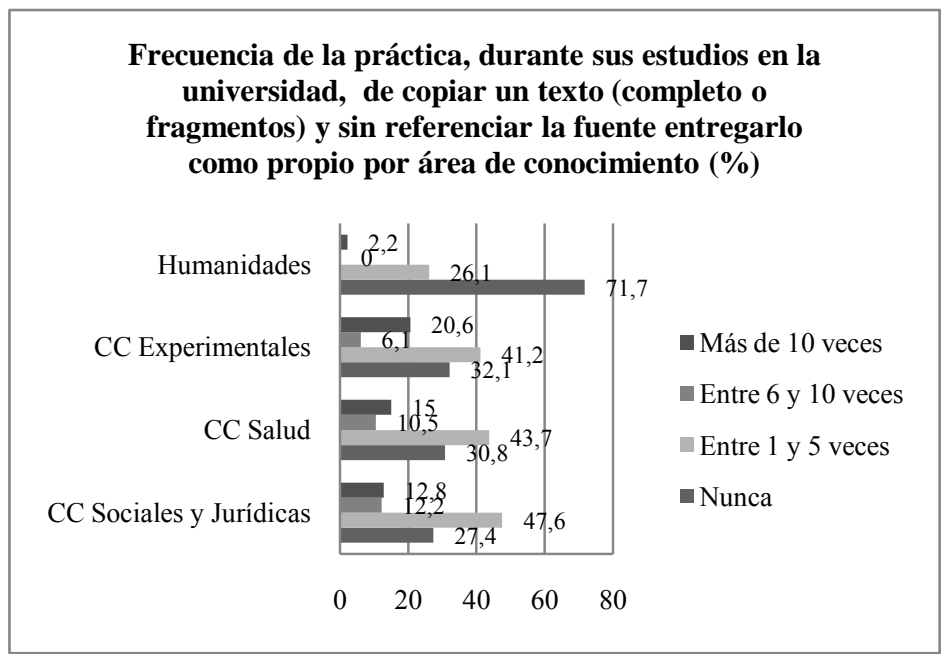

Según se desprende de los datos obtenidos por el estudio (ver Gráfica 4), los universitarios de la UIB presentan ratios de frecuencia levemente superiores a las universitarias cuando se trata de manifestar la prevalencia en el ejercicio de autoplagiarse a la hora de elaborar y entregar trabajos académicos.

\section{Gráfica 4:}

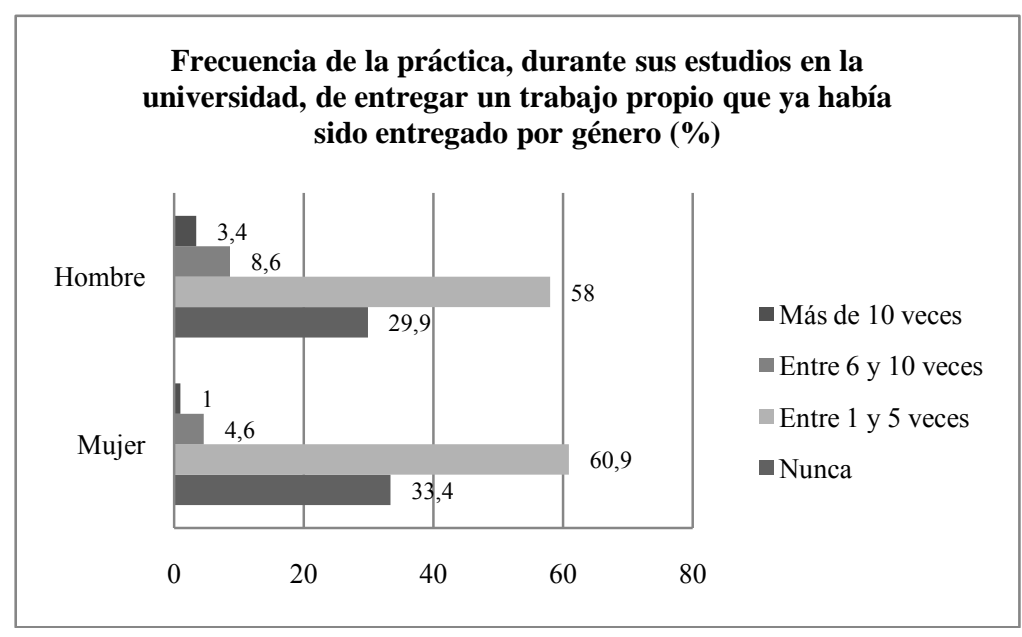

Rubén Comas Forgas, Jaume Sureda Negre y Miquel Oliver Trobat 


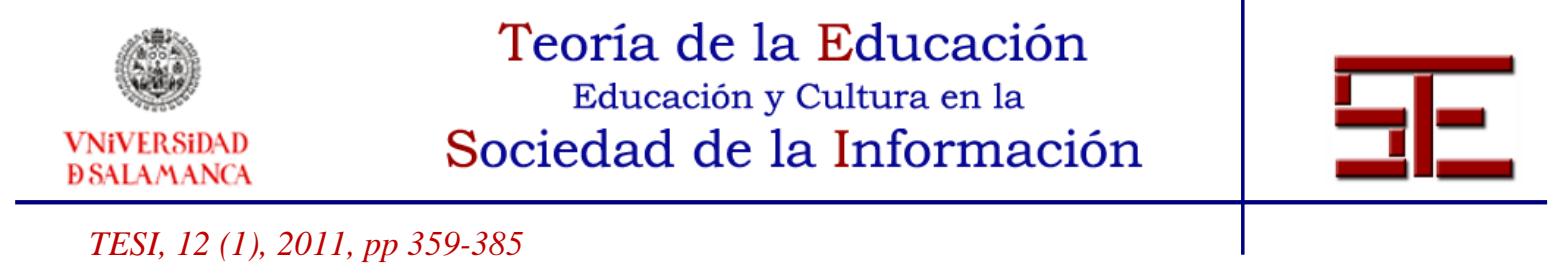

\subsection{Cumplimiento de las normas de citación a la hora de elaborar trabajos académicos por parte del alumnado universitario}

Poco más del $15 \%$ de la muestra de alumnado de la UIB afirma citar siempre la procedencia de las tablas o gráficas que emplea cuando hace trabajos (ver Tabla VI). Más de ocho de cada diez encuestados (82.9\%) manifiestan no citar siempre las tablas y gráficas que usan en la confección de un trabajo académico.

\begin{tabular}{|l|l|l|}
\hline $\begin{array}{l}\text { Cuando incorporas una tabla o gráfico a un trabajo: } \\
\text { indicas siempre la fuente de procedencia? }\end{array}$ & $\mathbf{N}$ & Porcentaje \\
\hline Sí & 160 & $15,6 \%$ \\
\hline No & 850 & $82,9 \%$ \\
\hline No sabe / No contesta & 15 & $1,5 \%$ \\
\hline Total & $\mathbf{1 . 0 2 5}$ & $\mathbf{1 0 0 \%}$ \\
\hline
\end{tabular}

Tabla VI. Frecuencia de citación de tablas y gráficas en los trabajos del alumnado

Como ilustra la Tabla VII, las posiciones extremas en la gradación de la respuesta a la pregunta de si el alumnado cita los recursos digitales que usa cuando elabora un trabajo académico son muy similares (un 19.5\% admite nunca citar las fuentes digitales que usa para hacer trabajos y un $18,4 \%$ manifiesta hacerlo siempre). Casi una tercera parte de la muestra (34.6\%) manifiesta citar los recursos digitales que emplea en sus trabajos de manera esporádica. Un $26.6 \%$ del alumnado de la UIB participante en el estudio declara citar los recursos digitales que emplea para hacer trabajos académicos "a menudo" y "mиу а menudo".

\begin{tabular}{|l|l|l|}
\hline $\begin{array}{l}\text { Cuando utilizas información que has localizado en Internet para hacer un trabajo: } \\
\text { ¿Referencias en el trabajo el lugar del que has obtenido dicha información? }\end{array}$ & $\mathbf{N}$ & Porcentaje \\
\hline No, nunca lo hago & 200 & $19.5 \%$ \\
\hline Sí, lo hago a veces & 354 & $34.6 \%$ \\
\hline Sí, lo hago a menudo & 162 & $15.8 \%$ \\
\hline Sí, lo hago muy a menudo & 111 & $10.8 \%$ \\
\hline Sí, lo hago siempre & 189 & $18.4 \%$ \\
\hline No sabe / No contesta & 9 & $0.9 \%$ \\
\hline Total & $\mathbf{1 . 0 2 5}$ & $\mathbf{1 0 0 \%}$ \\
\hline
\end{tabular}

Tabla VII. Frecuencia de citación de recursos digitales empleados en los trabajos del alumnado

De la prueba de asociación entre las variables estudiadas en este sub-ámbito de análisis y las categorías en que se ha dividido a la muestra, destaca la existencia de asociaciones significativas en: la categoría área de conocimiento cuando se relaciona con la práctica de citar las tablas y gráficas empleadas en la elaboración de un trabajo académico; las categorías curso matriculado y, nuevamente, área de conocimiento en la asociación con

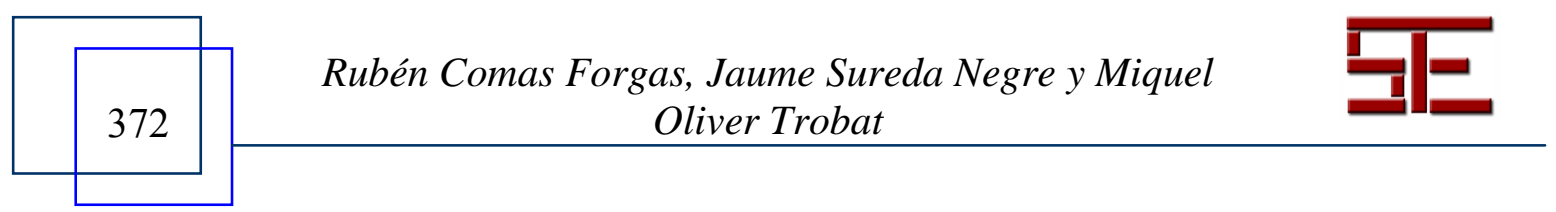




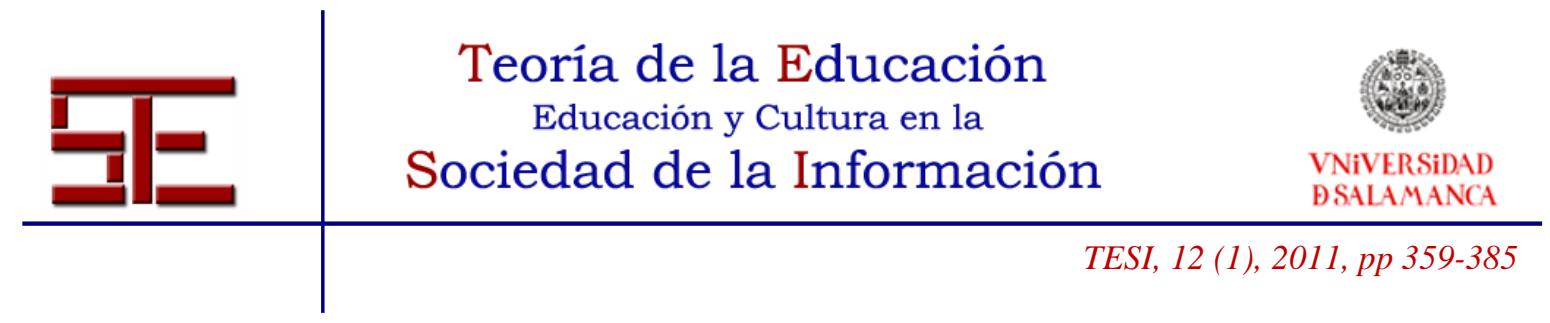

la práctica de referenciar los recursos digitales que se usan en la confección de un trabajo académico (ver Tabla VIII).

\begin{tabular}{|l|l|l|l|l|l|l|l|l|}
\hline & \multicolumn{9}{|l|}{$\begin{array}{l}\text { Indicar la fuente de procedencia de tablas } \\
\text { y gráficas }\end{array}$} & \multicolumn{3}{l|}{$\begin{array}{l}\text { Referenciar los recursos digitales que } \\
\text { emplean }\end{array}$} \\
\hline $\begin{array}{l}\text { Características de la } \\
\text { muestra }\end{array}$ & $\chi^{2}$ & $p$ & g.l. & $\mathbf{n}$ & $\chi^{2}$ & $\boldsymbol{p}$ & g.l. & $\mathbf{n}$ \\
\hline Género & 1,897 & 0,168 & 1 & 1.108 & 12,189 & 0,016 & 4 & 1.014 \\
\hline Curso matriculado & 7,639 & 0,103 & 4 & 1.010 & $107,058^{*}$ & 0,000 & 16 & 1.016 \\
\hline Área de conocimiento & $26,227^{*}$ & 0,000 & 3 & 1.010 & $34,041^{*}$ & 0,001 & 12 & 1.016 \\
\hline
\end{tabular}

Tabla VIII. Valor de la prueba de chi-cuadrado de Pearson para la asociación entre el cumplimiento de las normas de citación de trabajos académicos y las características del alumnado

$\chi^{2}$ Chi-cuadrado de Pearson // p Significación // g.l. Grados de libertad // * Significativa al nivel 0,01 (bilateral) // $\mathrm{n} \mathrm{N}^{\mathrm{o}}$ alumnos de la muestra

El alumnado de la UIB perteneciente a carreras del área de las Humanidades es el que muestra niveles de frecuencia superiores ante la cuestión de si cita siempre las tablas y figuras que emplea en sus trabajos: el 30.2\% manifiesta hacerlo siempre (ver Gráfica 5). En el polo opuesto se encuentran los alumnos matriculados en estudios del área de las Ciencias Experimentales (6.7\% de éstos citan siempre las tablas y gráficas que emplean en su trabajos); mientras que con guarismos muy parecidos se posiciona el alumnado de Ciencias de la Salud (8.4\% cita siempre las tablas y gráficas).

\section{Gráfica 5:}

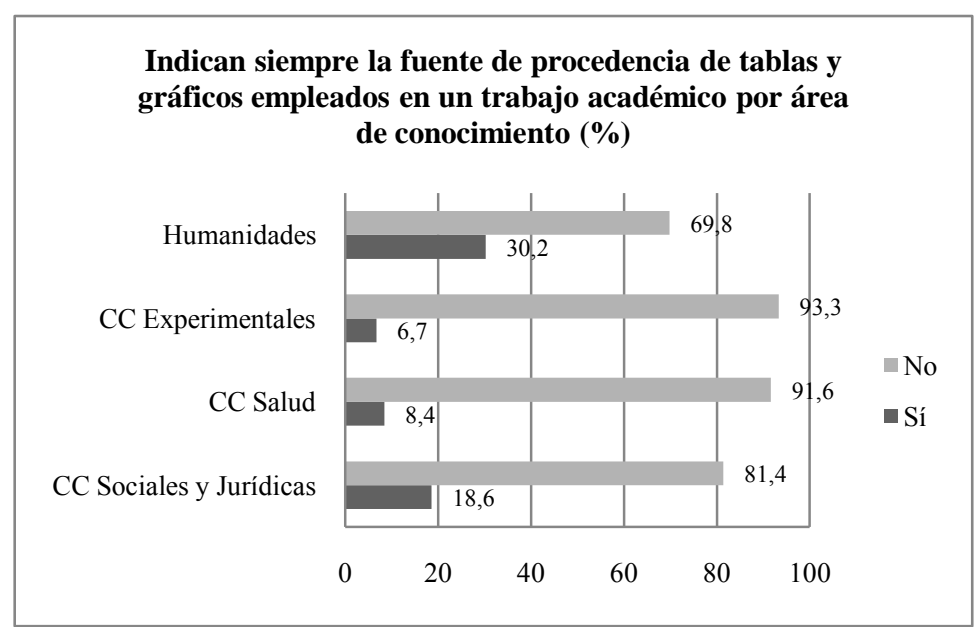

Rubén Comas Forgas, Jaume Sureda Negre y Miquel Oliver Trobat 


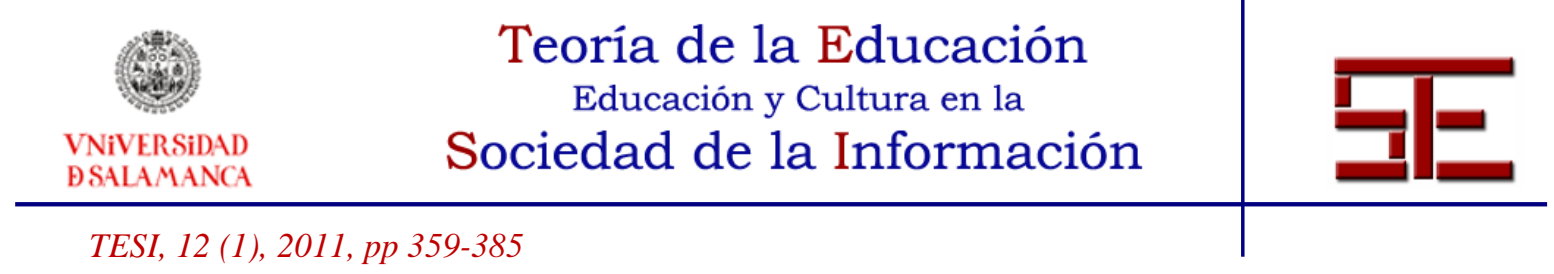

Se produce la circunstancia, a tenor de los resultados obtenidos de que el alumnado de cursos superiores o también llamados de segundo ciclo (cuarto y quinto) es el que cita más frecuentemente los recursos digitales que usa para hacer trabajos académicos (ver Gráfica 6). Los de primer y segundo curso son los que lo hacen con una frecuencia más baja; mientras que los de tercer año presentan niveles intermedios.

\section{Gráfica 6:}

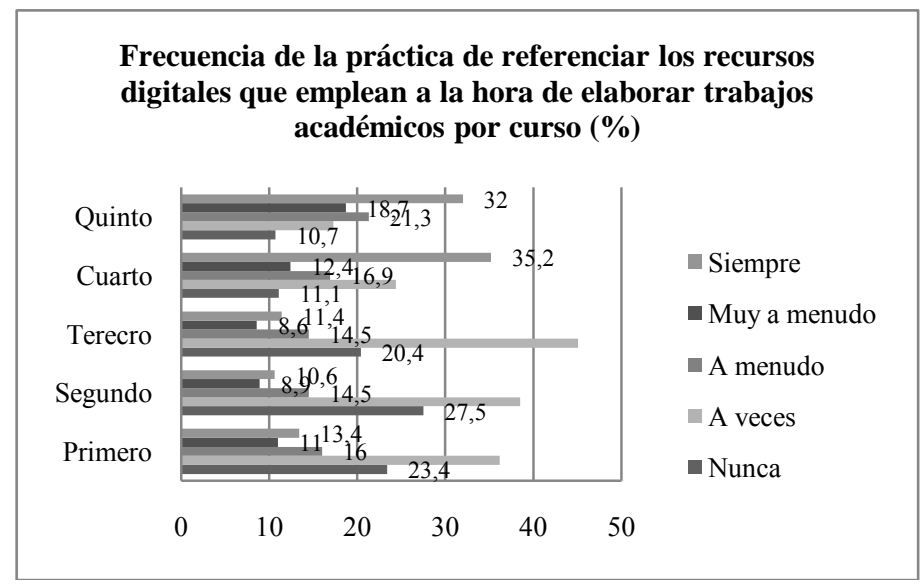

Los alumnos de Humanidades (ver Gráfica 7) son los que mayores tasas de frecuencia presentan en relación a la práctica de citar los recursos digitales que utilizan para preparar trabajos. El resto de grupos se mueve en niveles muy similares entre sí; acaso destacar que el alumnado de Ciencias Sociales y Jurídicas $(21.2 \%)$ y el de Ciencias Experimentales $(20.2 \%)$ son los que atesoran niveles más altos en el hábito de nunca citar las fuentes digitales que consultan para hacer trabajos.

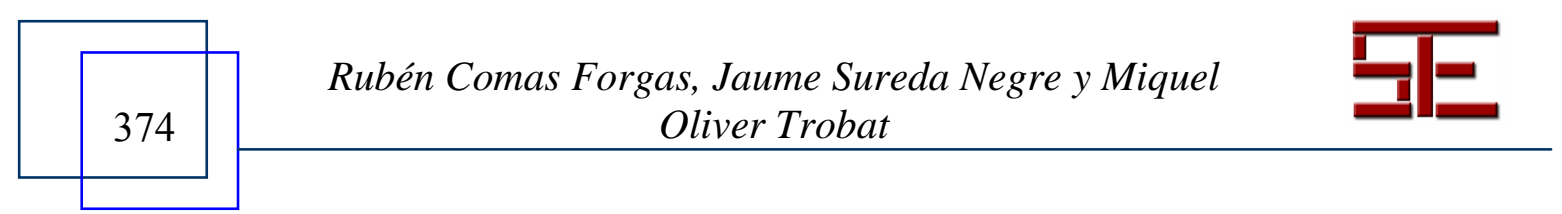




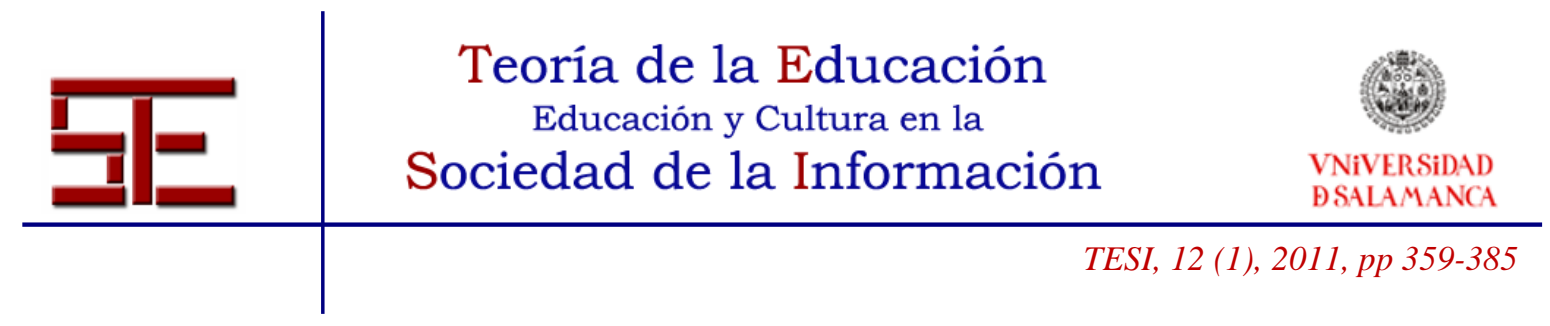

\section{Gráfica 7:}

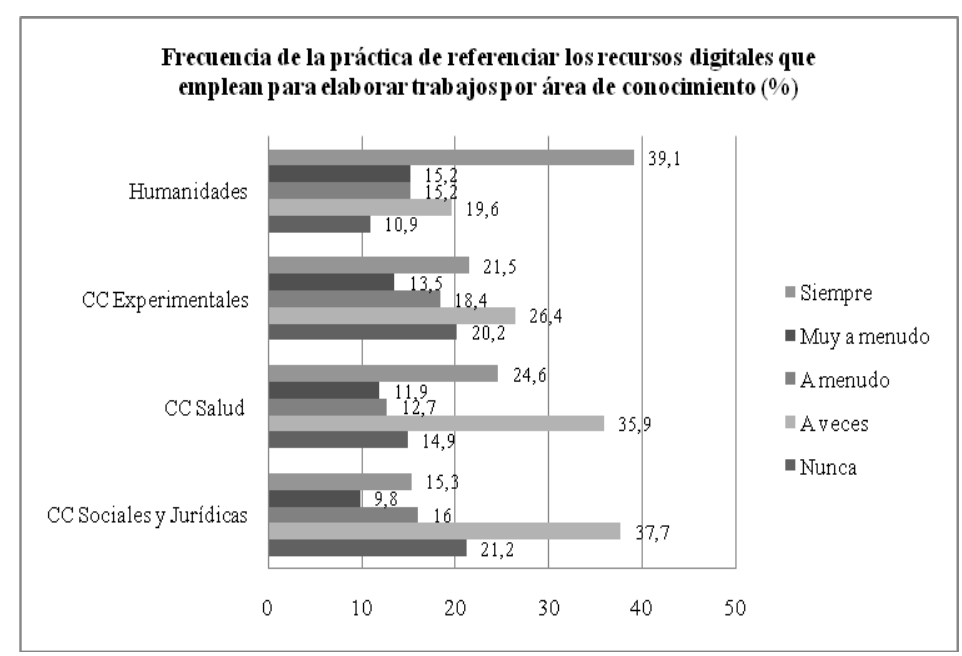

\section{4.- CONCLUSIONES Y DISCUSIÓN}

A la luz de los resultados alcanzados en el estudio, de lo primero que queda constancia y conviene resaltar es la disonancia existente entre los datos obtenidos en las dos dimensiones analizadas. Por un lado, prácticas académicamente deshonestas como son el plagio y autoplagio están considerablemente extendidas entre la comunidad estudiantil de la UIB; mientras que las prácticas de citación de recursos, a la hora de elaborar trabajos académicos, son notablemente infrecuentes entre dicho colectivo. Siendo más precisos y ahondando en la exposición, corresponde añadir que: en cuanto a la manifestación de comisión de plagio y auto-plagio, el perfil tipo del alumno que presenta mayor índice de prevalencia en la admisión de consumación de estas prácticas sería el de un estudiante (hombre) de primeros años de carrera cursando titulaciones propias del área de las Ciencias Experimentales. Mientras que, en el polo opuesto -es decir, el perfil de alumnado con un índice de auto-respuesta menor de comisión de plagio y auto-plagio- estaría representado por: una alumna de últimos cursos (cuarto y quinto) de carreras propias del área de Humanidades. Una lectura expresada en términos parecidos acerca de las prácticas de citación de recursos en la elaboración de trabajos nos devuelve que el perfil tipo de alumno que manifiesta citar recursos con mayor frecuencia es el de: una alumna de últimos cursos de carrera de estudios encuadrados en el área de Humanidades. El alumnado de la UIB que declara frecuencias más bajas en este apartado está representado por: un alumno (hombre) de primeros cursos de

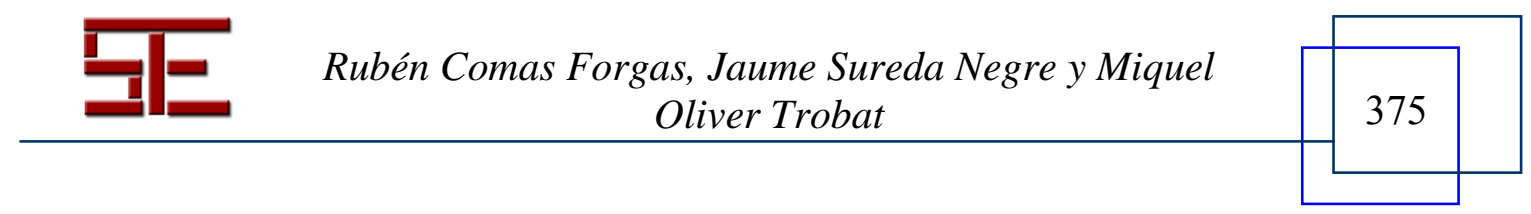




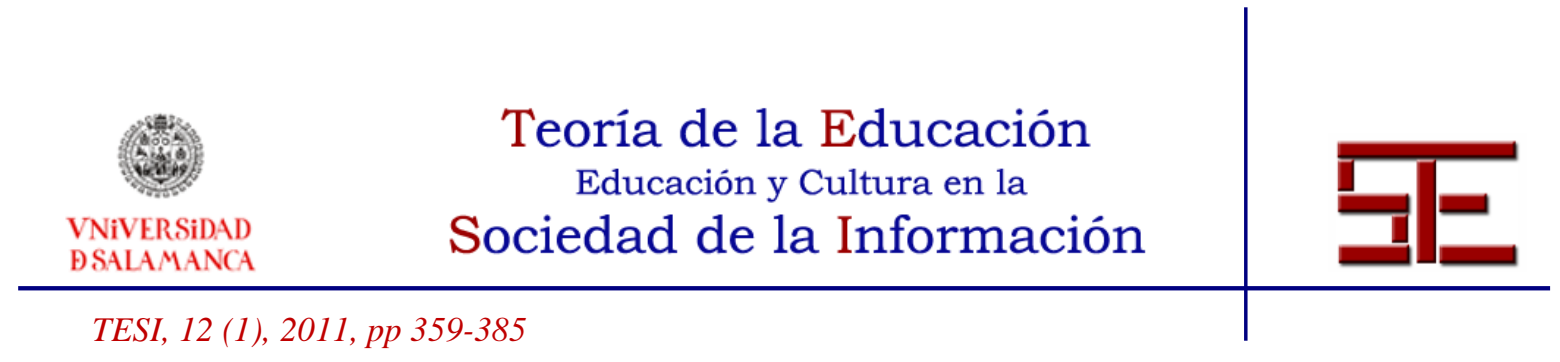

titulaciones de Ciencias Experimentales. Por tanto, ya no sólo es que los resultados globales presenten condiciones disonantes entre sí: lo mismo sucede cuando éstos son considerados atendiendo a las variables de categoría estudiadas (género, área de conocimiento y curso). Se constata, por tanto, una significación y una relación notable entre las dos dimensiones analizadas: a mayor admisión de la comisión de plagio y auto-plagio menor prevalencia en las prácticas de citación y a la inversa. Dándose dicha circunstancia tanto en los resultados totales como en la ponderación por categorías del alumnado estudiadas.

El escenario descrito guarda una estrecha similitud con el que se aprecia a partir de la lectura de estudios de análogas características, sirvan de ejemplo los resultados relativos a la frecuencia de comisión de plagio y auto-plagio mostrados por los estudios de Sureda y otros (2008a y 2008b) basados, respectivamente, en una encuesta administrada a 727 alumnos preguaduados de la Universidad de las Islas Baleares y a 560 universitarios pregraduados españoles adscritos al portal UNIVERSIA; el primero de los estudios arroja cifras que sitúan la prevalencia en la comisión de plagio académico usando Internet en un $76.6 \%$ de la muestra, mientras que la comisión de auto-plagio fue admitida por un $57.4 \%$ de los participantes en la encuesta. De este mismo estudio se desprende que el $59.4 \%$ del alumnado desconoce norma o estilo de citación alguno a la hora de elaborar sus trabajos académicos, siendo el alumnado de Humanidades el que presenta niveles más altos de conocimiento de este tipo de normativa (un $89.1 \%$ manifestó conocer al menos un estilo de citación) y el de Ciencias Experimentales y Ciencias Sociales y Jurídicas el que manifiesta niveles más bajos en esta cuestión (un $33.6 \%$ del alumnado de Ciencias Experimentales y un 35.9\% del grupo de Ciencias Sociales manifestaron conocer alguna norma de citación). Del segundo de los trabajos enunciados destaca el hecho de que el $59.4 \%$ de la muestra admitió haber plagiado trabajos de Internet, mientras que el $48.9 \%$ admitió haber cometido, en al menos una ocasión durante sus estudios universitarios, auto-plagio. Del mismo estudio se desprende que el $28.2 \%$ del alumnado encuestado no conoce ninguna norma de citación.

Datos extraídos del trabajo de Blanch-Mur, Rey-Abella y Font-Soler (2006), cimentado sobre una encuesta contestada por 468 alumnos de la Escuela Universitaria de Enfermería, Fisioterapia y Nutrición Blanquerna, sitúan en el 20\% la prevalencia de alumnado que admitió haber copiado textos completos o fragmentos y haberlos presentado como propios en forma de trabajo para alguna asignatura en la universidad.

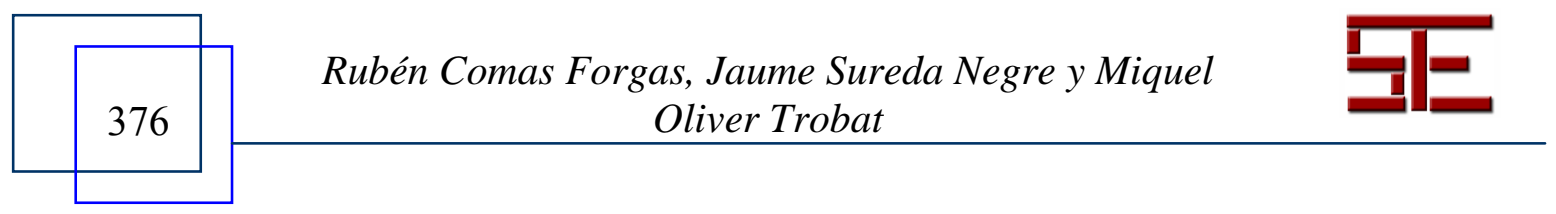




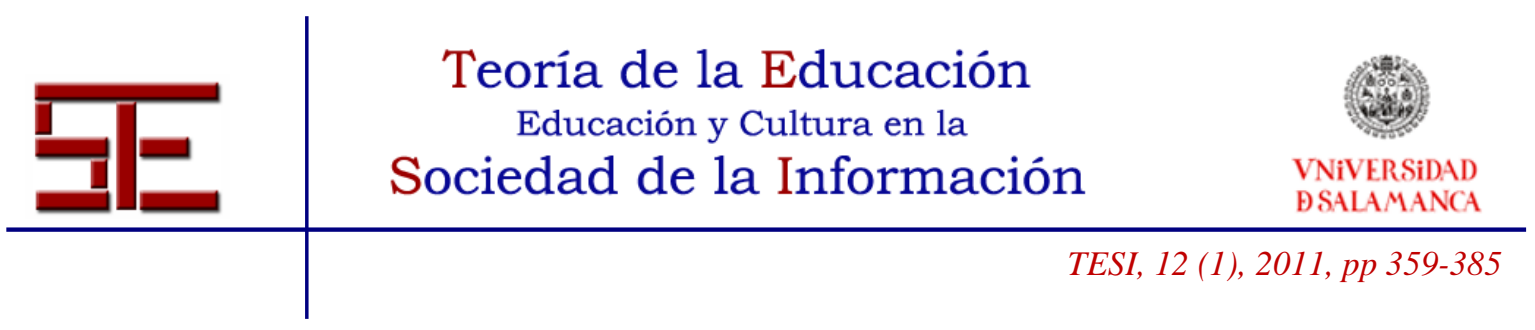

Aportes de un estudio cuantitativo realizado en las universidades españolas de Barcelona y Zaragoza con una muestra de 299 alumnos pre-graduados cifran en más del $90 \%$, en concreto, $93 \%$, el porcentaje de alumnado que admitió haber cometido plagio, alguna vez, en la elaboración de un trabajo durante sus estudios universitarios (Agnes, 2008). Otro aspecto relevante del mismo trabajo, esta vez con una muestra compuesta por 53 docentes universitarios de ambas instituciones, son las cifras de profesores que se han encontrado alguna vez con un trabajo plagiado: el $80 \%$ de los participantes afirmó haberse visto ante tal situación.

Resultados relativos a un estudio realizado mediante encuesta entre una muestra de 270 alumnos pre-graduados de la universidad mexicana Tecmilenio (Sureda et al., 2008) cifran en $44.3 \%$ el porcentaje de encuestados que admitió haber copiado, al menos una vez, fragmentos de texto extraídos de Internet y haberlos presentado como propio en forma de trabajo académico.

A modo de vasos comunicantes, a simple vista y en cierta lógica, parece que ambos factores -la comisión de plagio y la no utilización de citas en la elaboración textual por parte del alumnado- se retroalimentan. La cuestión, llegados a este punto, está situada, a nuestro entender, en qué fue primero o dónde recae el acento de la causalidad originaria: en el plagio como estrategia o procedimiento o en la mala praxis y/o desconocimiento de los principios de citación de recursos a la hora de redactar un trabajo académico. Parece evidente, al menos así pensamos quienes firmamos este trabajo, que si el alumnado citara -y además lo hiciera adecuadamente- todos los recursos y fuentes de las que se ha nutrido para elaborar un trabajo no cabría la posibilidad de plagio y no estaríamos delante de datos como los que aquí se despliegan. A este respecto, sostiene Rodríguez (2008) que 'el 'tema de la bibliografia' es sumamente engorroso para estudiantes universitarios y otros profesionales menos avezados en estos asuntos, $e$ incluso, algunos renuncian a reconocer los materiales que han contribuido a la realización de su trabajo". Por tanto, la duda puede comenzar a resolverse a partir de este primer axioma. Tal y como exponen Mages y Garson (2010), buena parte del corpus documental existente acerca de las ineficientes o inexistentes prácticas de citación entre el alumnado señala que -ya sea de manera singular o de manera conjunta: las variaciones y diferencias culturales en los estándares relativos a la creación escrita, el desconocimiento por parte del alumnado de los principios normativos de citación académica $\mathrm{y}$, en tercer lugar, el uso masivo de fuentes electrónicas son factores que explican las dificultades y déficits que presenta el alumnado a la hora de citar recursos

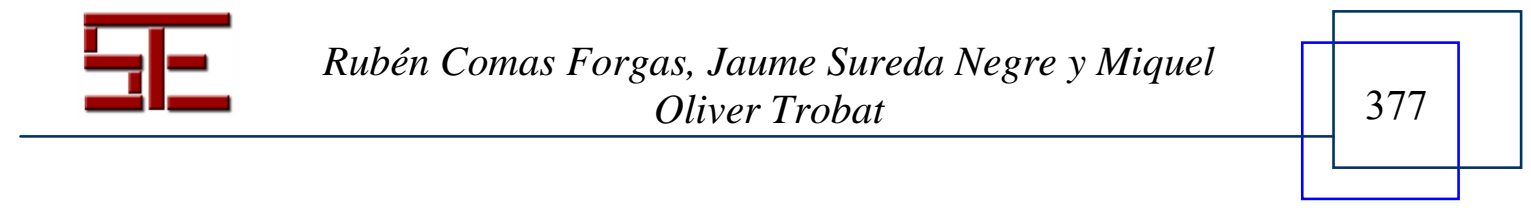




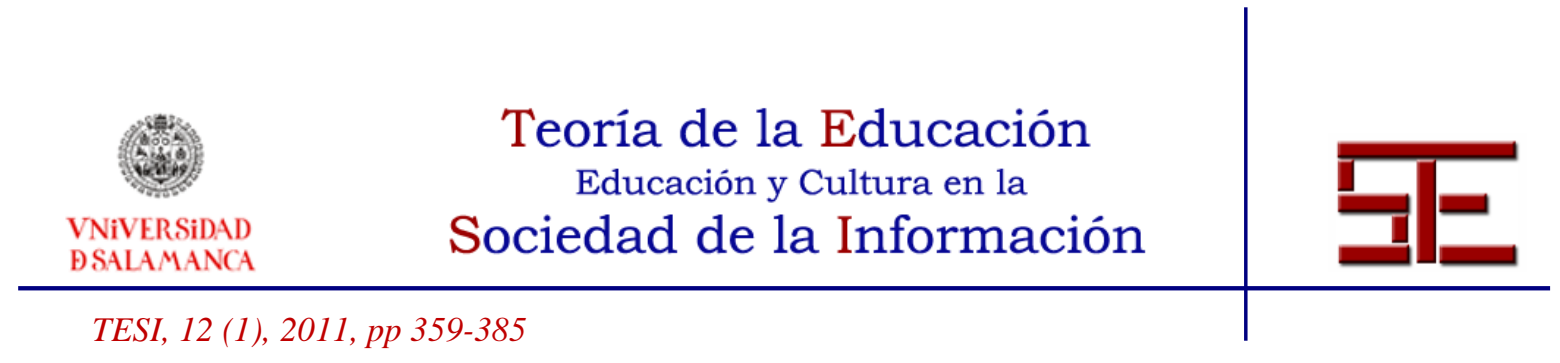

en sus creaciones académicas. Dejando de lado el primero de los argumentos, dado que parece tener un difícil encaje en la situación analizada, nos interesa centrar la atención en los dos restantes. La combinación de, por un lado, alumnado desconocedor de las normas y usos deseables en la creación escrita en ámbitos académicos y, en segundo lugar, las posibilidades que confieren las TIC para acceder y procesar (copiar, pegar, editar, etc.) información escrita de manera anónima y sencilla hacen que nos encontremos ante un mapa de situación que declama ser revisado de inmediato.

Volviendo al inicio de nuestra exposición, en páginas iniciales constatábamos como uno de los principales cambios que se vienen dando en la institución universitaria española, en el marco del EEES, es precisamente la mayor demanda de trabajos (creación escrita en la mayoría de casos) por parte del profesorado. Siendo así las cosas, y tomando buena nota de los datos existentes cabe plantearse la cuestión de qué potencial instructivo o educativo tiene esta estrategia metodológica si, según parece, el alumnado no sabe cómo hacer trabajos y en muchas ocasiones a lo que se dedica es a, simplemente, almacenar contenido sin aparente ejercicio ni resultante cognitivo que pueda ser calificado como de aprendizaje profundo y no se quede en la superficialidad de la acción recopiladora.

$\mathrm{Y}$ ante este escenario, qué hacer. Nos parece importante, en primer término, conocer y reconocer el problema. Para ello es necesario que se dediquen mayores esfuerzos a la investigación y conocimiento de la situación $\mathrm{y}$, sobre todo, de las causas que la sostienen y alimentan. En este sentido, aparte del hecho más o menos latente de que el alumnado no sepa elaborar trabajos con arreglo a los principios académicos básicos es también cierto que algunos tipos de trabajos que se prescriben por parte de los docentes son una especie de llamada e invitación a la recopilación de información por parte del alumnado y, por ende, en no pocas ocasiones suscitan la adopción de una estrategia basada en el "copia y pega" por parte del alumnado. A la vez, los indicios aquí presentados hacen necesario el planteamiento de la puesta en práctica de un plan de intervención directa, si hablamos de la institución universitaria, en forma y manera de formación y capacitación del alumnado en competencias propias de la ALFIN. En este sentido, creemos, del mismo modo, necesaria la planificación de estrategias formativas, desde el carácter transversal de la temática, dirigidas a alumnado pre-universitario como elemento integrante del currículo y la formación básica.

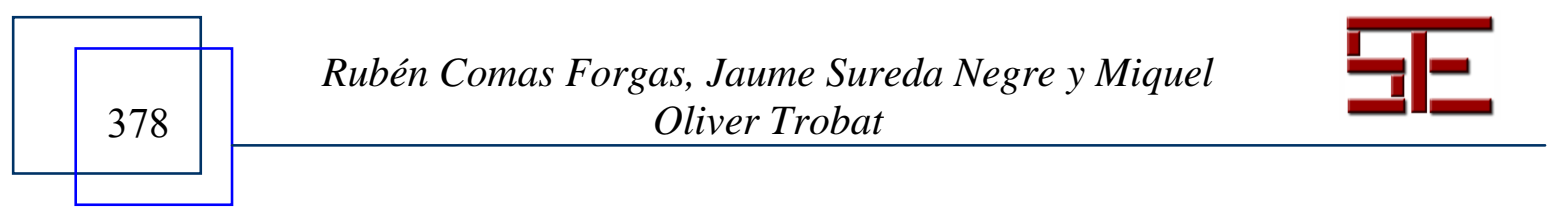




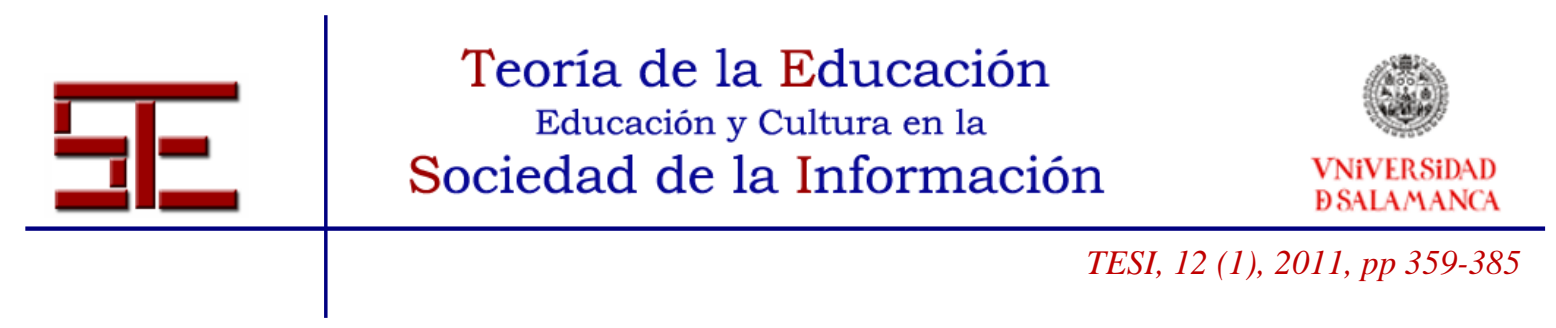

\section{5.- REFERENCIAS}

ACRL/ALA (2000). Information Literacy Competency Standards for Higher

Education. Extraído el 12 de septiembre de 2010, de

http://www.ala.org/acrl/ilcomstan.html.

Aditaka, A. \& Anwar, M. (2006). Student library use: a study of faculty perceptions in a Malaysian university. Librabry review, vol. 55 (2). 106-119.

Agnes J. (2008). Los usos de Internet en la educación superior: de la documentación al plagio. Six Degrés. Extraído el 12 de septiembre de 2010, de http://www.compilatio.net/files/080521_sixdegres-univ-barcelona_univzaragoza_encuesta-plagio.pdf.

Agosto, D., Paone, K. \& Ipock, G. (2007). The Female-Friendly Public Library: Gender Differences in Adolescents' Uses and Perceptions of U.S. Public Libraries. Library Trends, vol. 56 (2). 387-401.

Arias, A. \& Simón, J. (2008). Estudio de los hábitos de uso de los estudiantes en la biblioteca de la Universidad Complutense de Madrid. Revista Española de Documentación Científica, vol. 31 (3). 413-431.

Asefeh, A. (2005). Familiarity and Use of Digital Resources by students in Academic Libraries in MUI. En Proceeding of Fourth Annual Seminar of Iranian Students in India: Information Technology \& it's Application In Sciences. The Union of The

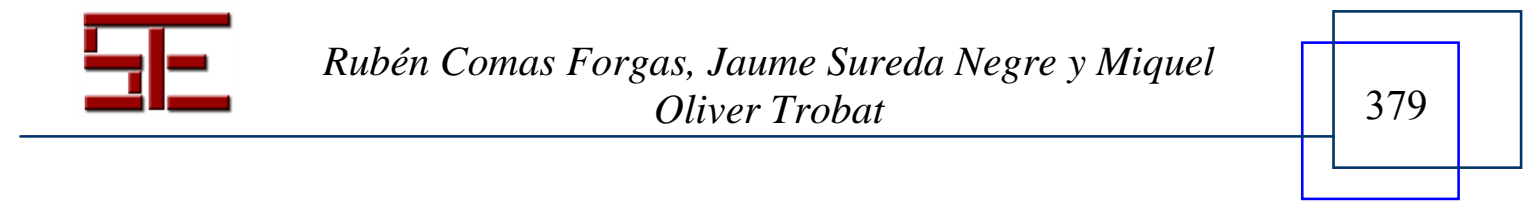




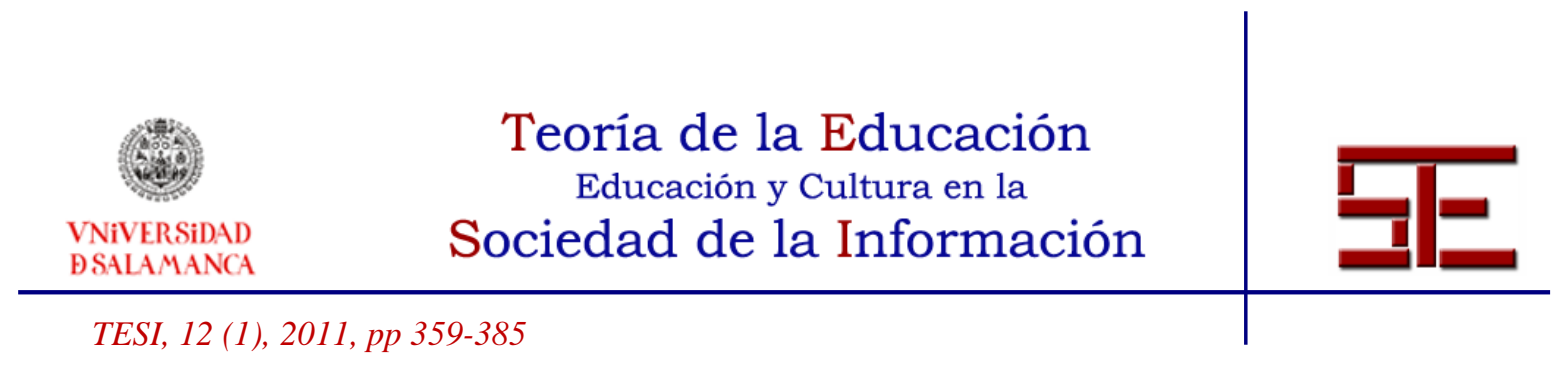

Iranian Student's Islamic Association- India \& Director Science, Research and Technology Embassy of I.R.Iran, 10 $0^{\text {th }}-11$ th March.

Baer, W. \& Li, L. (2009). Library and information use patterns by engineering faculty and students. En ASEE Annual Conference 2009, Austin, TX. Extraído el 12 de septiembre de 2010, de https://smartech.gatech.edu/bitstream/1853/28688/1/EngLibSurvey-Bear-Li.pdf.

Ballano, I. \& Muñoz, I. (2009). TIC y discurso académico: algunas consecuencias del ciberplagio. Extraído el 12 de septiembre de 2010, de http://meb.sev.gob.mx/difusion/tecnologias.pdf.

Bawden, D. (2000). Revisión de los conceptos de alfabetización informacional y alfabetización digital. Anales de Documentación, 5. 361-408. ISSN: 1575-2437.

Blanch-Mur, C.; Rey-Abella, F. \& Font-Soler, A. (2006). Nivel de conducta académica deshonesta entre los estudiantes de una escuela de ciencias de la salud. Enfermería Clínica, 16 (2). 57-61.

Brabazon, T. (2007). The University of Google: Education in the (Post) Information Age. London: Ashgate.

CAUL (2001). Information Literacy Standards. Canberra, Council of Australian University Librarians. Extraído el 12 de septiembre de 2010, de http://ilp.anu.edu.au/Infolit_standards_2001.html.

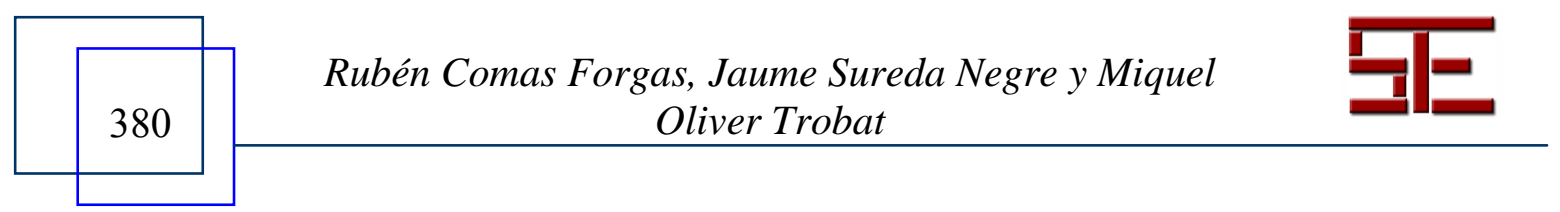




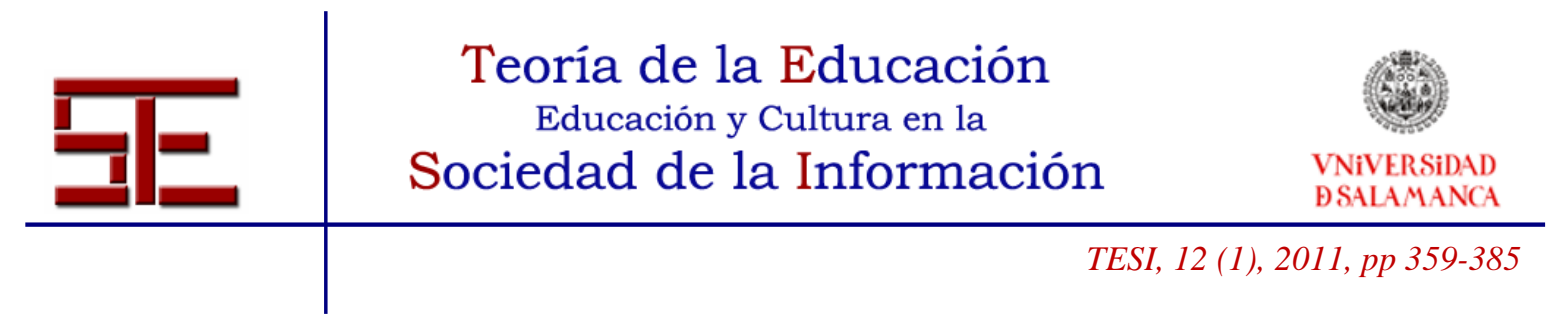

Cmor, D. \& Lippold, K. (2001). Surfing vs. searching: the Web as a research tool. Artículo presentado en la $21^{a}$ Annual Conference of the Society for teaching and Learning in Higher Education. Extraído el 12 de septiembre de 2010, de www.mun.ca/library/reseacg_help/qeii/stlhe.

Comas, R. (2009). El cibeplagio académico entre el alumnado universitario. Tesis Doctoral no publicada. Universidad de las Islas Baleares, España.

Comas, R., Sureda, J. \& Mut, T. (2010). Uso de fuentes documentales -impresas y digitales- con fines académicos entre el alumnado universitario. Revista Electrónica de Tecnología Educativa 31. Extraído el 12 de septiembre de 2010, de http://edutec.rediris.es/revelec2/revelec31/.

Dyer, K. A. (2010). Challenges of Maintaining Academic Integrity in an Age of Collaboration, Sharing and Social Networking. TCC 2010 Proceedings. Extraído el 12 de septiembre de 2010, de http://etec.hawaii.edu/proceedings/2010/Dyer.pdf.

Garcia-Barbastefano, R. y Gomes-de-Souza, C. (2007). Percepção do conceito de plágio acadêmico entre alunos de engenharia de produção e ações para sua redução. Revista Produção, edición especial diciembre. Artículo extraído de los Anais do xxvii Encontro Nacional de Engenharia de Produção. Universidade Federal de Santa Catarina. Extraído el 12 septiembre de 2010, de http://producaoonline.org.br/index.php/rpo/article/view/52/52.

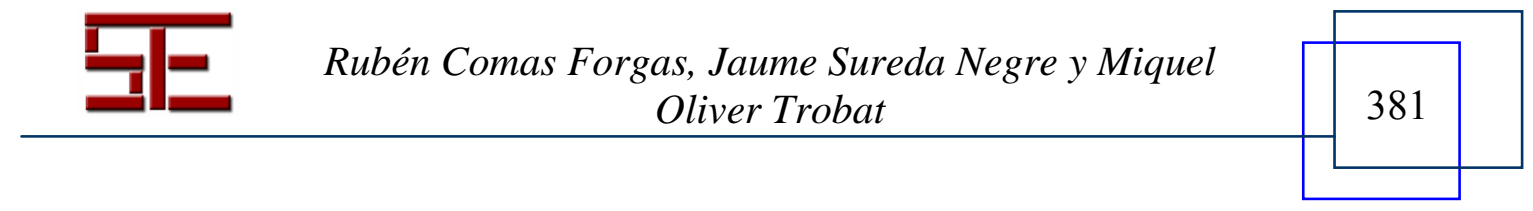




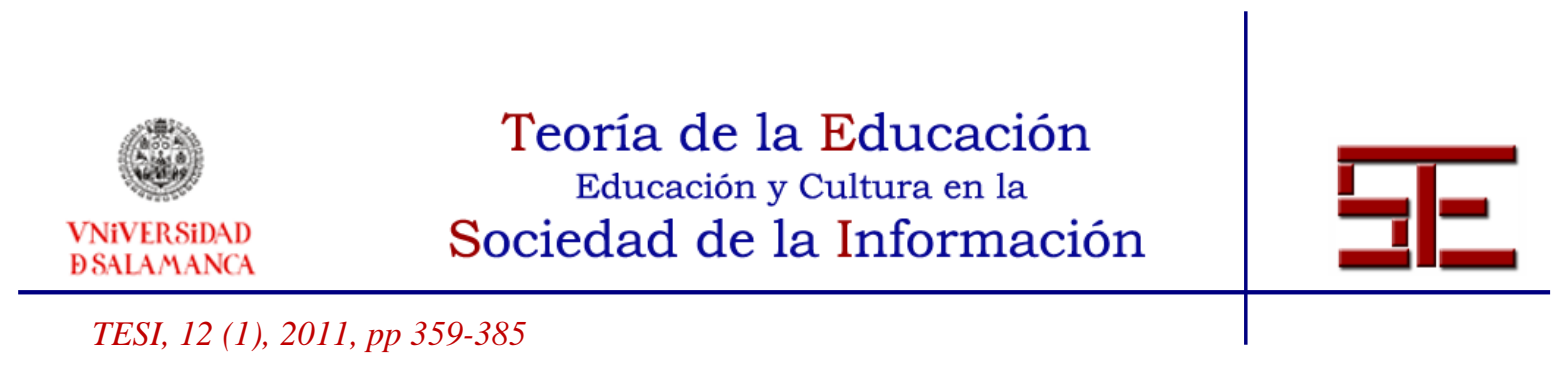

Griffiths, J. R. \& Brophy, P. (2002). Student searching behaviour in the JISC Information Enviroment. Ariadne, 33. Extraído el 12 septiembre de 2010, de http://www.ariadne.ac.uk/issue33/edner/.

Head, A. (2007). Beyond Google: how do students conducst academic research. First Monday, vol. 12 (8). Extraído el 12 septiembre de 2010, de http://firstmonday.org/htbin/cgiwrap/bin/ojs/index.php/fm/article/view/1998/1873.

Kuruppu, P. (2008). Information Use by PhD Students in Agriculture and Biology: A Dissertation Citation Analysis portal. Libraries and the Academy, vol. 8 (4). 387405.

Licea-de-Arenas, J. (2009). La alfabetización informacional en el entorno hispanoamericano. Anales de Documentación, 12. 93-106.

Mages, W. \& Garson, D. (2010). Get the cite right: Design and evaluation of a highquality online citation tutorial. Library \& Information Science Research, 32. 138146.

Martin et al. (2009). Closing the Gap: Investigating the Search Skills of International and US Students: An Exploratory Study. Library Philosophy and Practice. Extraído el 12 septiembre de 2010, de http://www.webpages.uidaho.edu/ mbolin/martinmaxeyharris-graybill-rodackerborgens.htm.

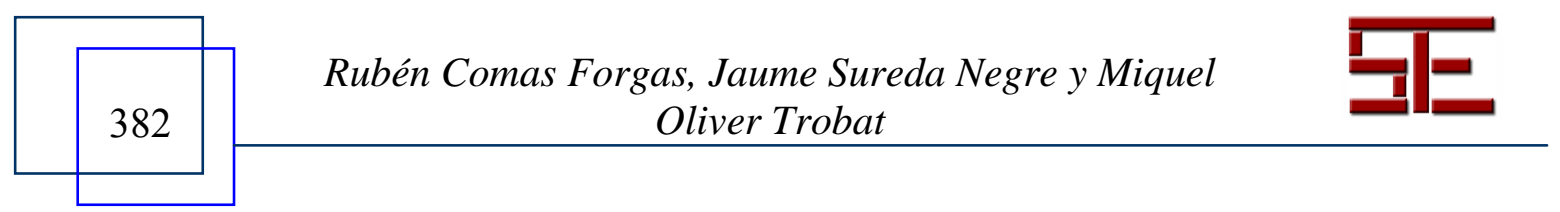




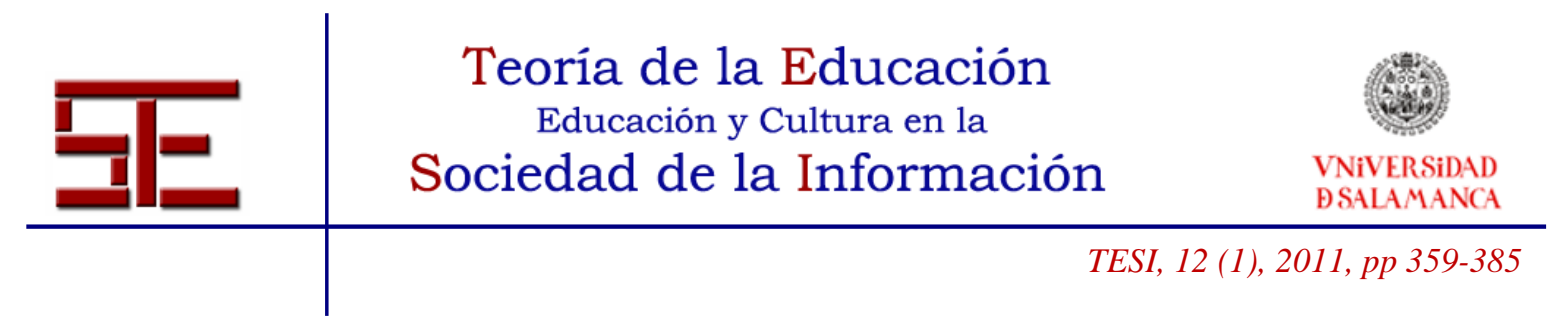

Marzal, M. \& Calzada, F. (2003). Un análisis de necesidades y hábitos informativos de estudiantes universitarios en Internet. Binaria: Revista de comunicación, cultura y tecnología, 3.

McMartin et al (2008). The use of online digital resources and educational digital libraries in higher education. International Journal of digital libraries, vol. 9, No 1. $65-79$.

Mejía, J. F. y Ordóñez, C. L. (2004). El fraude académico en la Universidad de los Andes. ¿Qué, qué tanto y por qué? Revista de Estudios Sociales, 18. 13-25.

Moreno-Ariza \& Pérez-Ferra, (2009). Cómo motivar a aprender en la universidad: una estrategia fundamental contra el fracaso académico en los nuevos modelos educativos. Revista Iberoamericana de Educación, 51. Extraído el 12 septiembre de 2010, de http://www.rieoei.org/rie51a04.htm.

Nwagwu, E. et. al (2009). Factors influencing use of the internet: A questionnaire survey of the students of University of Ibadan, Nigeria. The Electronic library, vol. 27 (4). 718-734.

Parang, E., Raine, M. \& Stevenson, T. (2001). Redesigning Freshman Seminar library instruction based on information competencies. Research Strategies, 17. 269280.

Rader, H. B. (2002). Information literacy 1973-2002: a selected literature review. Library Trends, 51. 242-259.

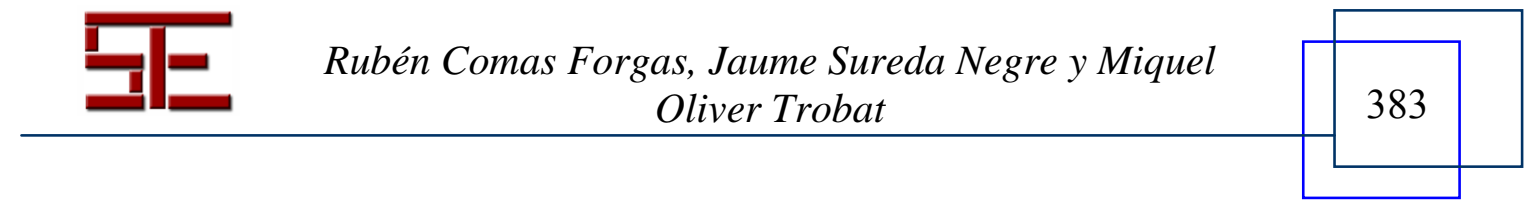




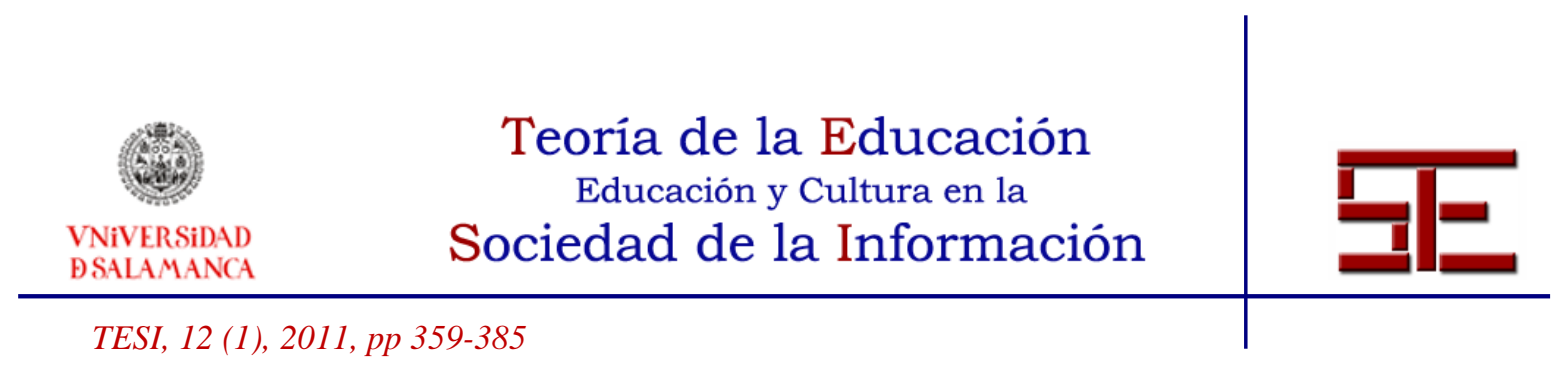

Rodríguez, L. (2008). ¿Le resulta difícil hacer la bibliografía? Los gestores de referencias bibliográficas pueden ayudarlo. Extraído el 12 septiembre de 2010, de http://biblioteca.catie.ac.cr.

Saldaña-Gastulo, J.; Quezada-Osoria, C., Peña-Oscuvilca, A. \& Mayta-Tristán, P. (2010). Alta frecuencia de plagio en Tesis de Medicina de una universidad pública peruana. Revista Peruana de Medicina Experimental y Salud Pública, 27(1). 63-67.

Sureda, J. \& Comas, R. (2006). Internet como fuente de documentación académica entre estudiantes universitarios. Palma de Mallorca: Fundación Universidad Empresa de las Islas Baleares. ISBN: 84-690-1270-3.

Sureda, J. et al. (2008a). El plagio y otras formas de deshonestidad académica entre el alumnado de la Universitat de les Illes Balears. Resultados generales. Informe de investigación del Grupo Educación y Ciudadanía. Palma: Universitat de les Illes Balears. Departamento de Pedagogía Aplicada y Psicología de la Educación. Extraído el 12 septiembre de 2010, de http://ciberplagio.es/attachment.php?key=37.

- (2008b). El plagio y otras formas de deshonestidad académica entre el alumnado de la Universidad de Tecmileion. Resultados generales. Informe de investigación del Grupo Educación y Ciudadanía. Palma: Universitat de les Illes Balears. Departamento de Pedagogía Aplicada y Psicología de la Educación. Extraído el 12 septiembre de 2010, de http://ciberplagio.es/attachment.php?key=39.

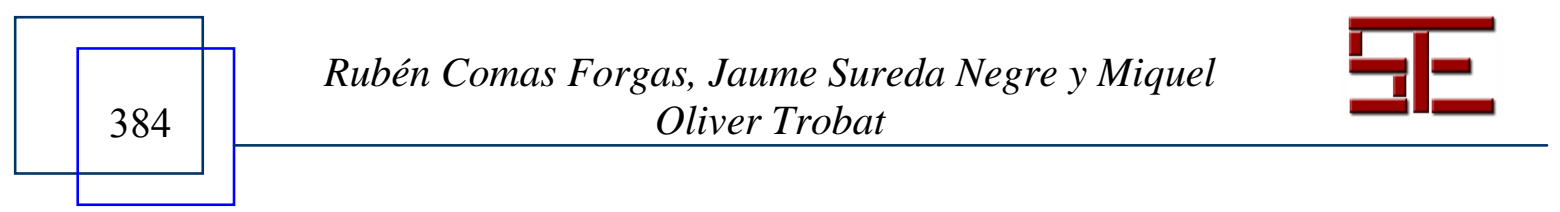




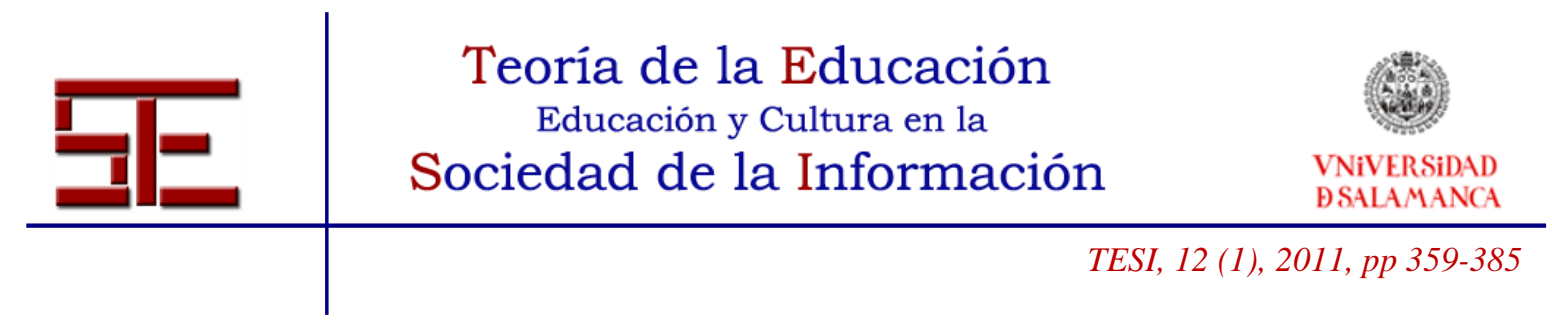

Vickery, S. \& Cooper, H. (2003). Confidence or Competence? - auditing information literacy skills of biology undergraduate students. EDUCAUSE in Australia 03. 498-505 ISBN 1-876346-47-7. Extraído el 12 septiembre de 2010, de http://www.caudit.edu.au/educauseaustralasia/2003/EDUCAUSE/PDF/AUTHOR/ED03 0011.PDF.

Vondracek, R. (2007). Comfort and Convenience? Why Students Choose Alternatives to the Library portal. Libraries and the Academy, vol.7 (3). 277-293.

Zhang, X., Anghelescu, H. y Yuan, X. (2005). Domain knowledge, search behaviour, and search effectiveness of engineering students: an exploratory study. Information Research, Vol. 10 (2). Extraído el 12 septembre de 2010, de http://informationr.net/ir/10---2/paper217.html.

\footnotetext{
${ }^{1}$ Datos obtenidos en un reciente estudio realizado en la Universidad de las Islas Baleares -España- cifran en algo más de catorce la media de trabajos que se prescriben por curso a un alumno pre-graduado universitario (Comas, 2009). Tomando como indicador de factor mínimo, al amparo de los cambios devenidos de la adaptación al Espacio Europeo de Educación Superior (EEES) en España, una permanencia de cuatro años en la institución universitaria, el dato anterior supone que un alumno tipo de una universidad tipo española elaborará alrededor de cincuenta trabajos académicos antes de obtener su titulación y acabar su formación.
}

Para citar el presente artículo puede utilizar la siguiente referencia:

Comas Forgas, R., Sureda Negre, J. y Oliver Trobat, M. (2011). Prácticas de citación y plagio académico en la elaboración textual del alumnado universitario, en Hernández Serrano, M. J. y Fuentes Agustí, M. (Coords.) La red como recurso de información en educación. Revista Teoría de la Educación: Educación y Cultura en la Sociedad de la Información. Vol. 12, n ${ }^{\circ}$ 1. Universidad de Salamanca, pp. 359-385 [Fecha de consulta: $\mathrm{dd} / \mathrm{mm} /$ aaaa $]$.

http://campus.usal.es/ revistas_trabajo/index.php/revistatesi/article/view/7837/7863

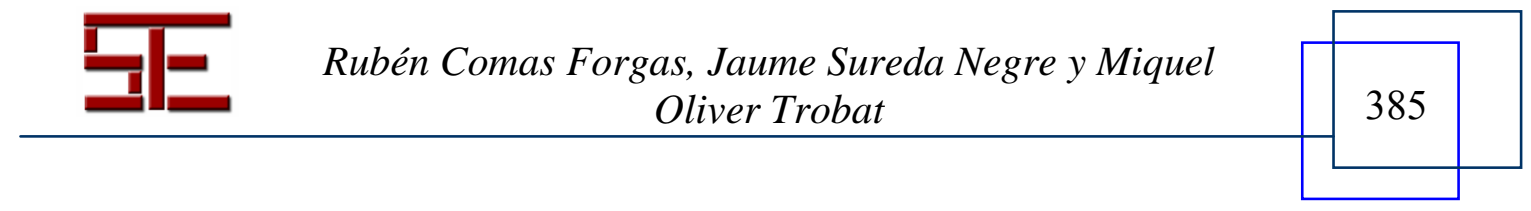

